\title{
Deafferentiation-Associated Changes in Afferent and Efferent Processes in the Guinea Pig Cochlea and Afferent Regeneration With Chronic Intrascalar Brain-Derived Neurotrophic Factor and Acidic Fibroblast Growth Factor
}

\author{
RUDOLF GLUECKERT, ${ }^{1,2}$ MARIO BITSCHE, ${ }^{1,2}$ JOSEF M. MILLER, ${ }^{3,4}$ YAYING ZHU, ${ }^{1}$ \\ DIANE M. PRIESKORN, ${ }^{3}$ RICHARD A. ALTSCHULER, ${ }^{3}$ \\ AND ANNELIESE SCHROTT-FISCHER ${ }^{1 *}$ \\ ${ }^{1}$ Department of Otolaryngology, Medical University of Innsbruck, A-6020 Innsbruck, Austria \\ ${ }^{2}$ University Clinics of Innsbruck, Tiroler Landeskrankenanstalten GmbH-TILAK, A-6020 \\ Innsbruck, Austria \\ ${ }^{3}$ Kresge Hearing Research Institute, University of Michigan, Ann Arbor, Michigan 48109-0506 \\ ${ }^{4}$ Center for Hearing and Communication, Karolinska Institutet, 17177 Stockholm, Sweden
}

\begin{abstract}
Deafferentation of the auditory nerve from loss of sensory cells is associated with degeneration of nerve fibers and spiral ganglion neurons (SGN). SGN survival following deafferentation can be enhanced by application of neurotrophic factors (NTF), and NTF can induce the regrowth of SGN peripheral processes. Cochlear prostheses could provide targets for regrowth of afferent peripheral processes, enhancing neural integration of the implant, decreasing stimulation thresholds, and increasing specificity of stimulation. The present study analyzed distribution of afferent and efferent nerve fibers following deafness in guinea pigs using specific markers (parvalbumin for afferents, synaptophysin for efferent fibers) and the effect of brain derived neurotrophic factor (BDNF) in combination with acidic fibroblast growth factor $(\mathrm{aFGF})$. Immediate treatment following deafness was compared with 3-weekdelayed NTF treatment. Histology of the cochlea with immunohistochemical techniques allowed quantitative analysis of neuron and axonal changes. Effects of NTF were assessed at the light and electron microscopic levels. Chronic BDNF/aFGF resulted in a significantly increased number of afferent peripheral processes in both immediate- and delayed-treatment groups. Outgrowth of afferent nerve fibers into the scala tympani were observed, and SGN densities were found to be higher than in normal hearing animals. These new SGN might have developed from endogenous progenitor/stem cells, recently reported in human and mouse cochlea, under these experimental conditions of deafferentation-induced stress and NTF treatment. NTF treatment provided no enhanced maintenance of efferent fibers, although some synaptophysin-positive fibers were detected at atypical sites, suggesting some sprouting of efferent fibers. J. Comp. Neurol. 507:1602-1621, $2008 . \quad \odot 2008$ Wiley-Liss, Inc.
\end{abstract}

Indexing terms: cochlea; nerve fiber regeneration; brain-derived neurotrophic factor; acidic fibroblast growth factor

Grant sponsor: European Community; Grant number: QLG3-CT-200201463; Grant sponsor: National Institutes of Health; Grant number: NIHNIDCD R01 DC003820; Grant number: P30 DC005188; Grant sponsor: Austrian Science Foundation; Grant number: P15948-B05; Grant sponsor: General Motors Corporation; Grant sponsor: Ruth and Lynn Townsend Professorship of Communication Disorders.
*Correspondence to: Prof. Anneliese Schrott-Fischer, Department of Otolaryngology, Medical University of Innsbruck, Anichstr. 35, A-6020 Innsbruck, Austria. E-mail: annelies.schrott@i-med.ac.at

Received 30 April 2007; Revised 17 July 2007; Accepted 3 December 2007 DOI 10.1002/cne.21619

Published online in Wiley InterScience (www.interscience.wiley.com). 
Deafferentation of the auditory nerve from loss of sensory cells (inner hair cells; IHC) is associated with the loss of auditory function. As IHC are damaged, they release excess glutamate, resulting in the swelling and bursting of the peripheral processes of the auditory nerve that had been connected to the IHC. These auditory nerve processes are capable of recovery and reconnecting if $\mathrm{IHC}$ recover (Puel et al., 1995, 1998); in the presence of massive IHC loss, however, these processes do not recover. The unmyelinated portion of the auditory nerve peripheral processes rapidly regresses to the habenula perforata, followed by a slower regression of myelinated portion toward the cell bodies of the auditory nerve [spiral ganglion neurons (SGN); Webster and Webster, 1981; Koitchev et al., 1982; Bichler et al., 1983; Spoendlin, 1984; Morest et al., 1998]. As with deafferentation-associated cell death in other systems, SGN apoptosis appears to be induced by the loss of survival factors, including neurotrophic factors, following IHC destruction (for reviews see Miller et al., 2002; Roehm and Hansen, 2005). Apoptosis of SGN (Roehm and Hansen, 2005) proceeds gradually over a period of time, with the rate of cell death occurring more rapidly in rat, mouse, chinchilla, or guinea pig (Webster and Webster, 1981; Koitchev et al., 1982; Bichler et al., 1983; Jyung et al., 1989; McFadden et al., 2004), compared with cat (Leake and Hradek, 1988) and primate, including man (Suzuka and Schuknecht, 1988; Nadol et al., 1989; Nadol, 1990, 1997; Zimmermann et al., 1995; Incesulu and Nadol, 1998). In the guinea pig, there is a large SGN loss by 2 months following hair cell loss (Webster and Webster, 1981; Jyung et al., 1989).

The loss of SGN can have serious clinical repercussions. Cochlear prostheses are now used to restore hearing successfully following deafness from sensory cell loss in large numbers of patients. Cochlear prostheses, however, depend on direct electrical stimulation of the auditory nerve neurons for their function, and loss of SGN can compromise their efficacy. Studies have now shown that SGN survival following sensory cell loss can be significantly enhanced by application of neurotrophic factors (NTF), such as brain-derived neurotrophic factor (BDNF; Staecker et al., 1996; Miller et al., 1997; Gillespie et al., 2003; Shepherd et al., 2005) neurotrophin-3 (NT-3; Ernfors et al., 1996), glial cell line-derived neurotrophic factor (GDNF; Ylikoski et al., 1998; Altschuler et al., 1999; Yagi et al., 2000), and combinations of neurotrophic factors such as BDNF and fibroblast growth factor (FGF; Altschuler et al., 1999) or BDNF and ciliary neurotrophic factor (CNTF; Yamagata et al., 2004). NFT are also involved in the formation and maintenance of afferent and efferent cochlear connections (Fritzsch et al., 2004) during normal development. The same NFT that enhance SGN survival might then also induce the regrowth of their peripheral processes, even in the absence of IHC (Ernfors et al., 1996; Staecker et al., 1996; Altschuler et al., 1999; Wise et al., 2005). Regrowth of peripheral processes could enhance the integration of implant and auditory nerve, increase electrode-nerve process proximity, lower excitatory thresholds, and increase selectivity of activation. This could, in turn, improve efficacy and function of cochlear prostheses. Previous studies, however, have used nerve fiber markers that could not differentiate whether the regrowth was from afferent processes of the auditory nerve, from lateral and medial efferent processes to the cochlea, or from some combination of afferents and effer- ents. Regrowth of lateral or medial efferents would have unknown benefit to the efficacy of cochlear prostheses. This study is based on the hypothesis that neurotrophic treatment selectively enhances afferent fiber regrowth and uses selective markers that differentiate afferent and efferent processes in the cochlea. Parvalbumin is a calcium-buffering protein that in the cochlea selectively labels SGN and their processes as well as IHC (Eybalin and Ripoll, 1990; Soto-Prior et al., 1995; Pack and Slepecky, 1995). Synaptophysin is a synaptic vesicleassociated protein that provides specific labeling of olivocochlear efferent fibers and terminals in the cochlea (GilLoyzaga and Pujol, 1988; Nadol et al., 1993; Knipper et al., 1995; Simmons et al., 1996; Counter et al., 1997). The present study used parvalbumin as a marker for the peripheral processes of the auditory nerve and synaptophysin as a marker for olivocochlear efferent peripheral processes in immunocytochemical investigation of the progression of deafness-associated changes in efferent and afferent peripheral processes and the influence of chronic intrascalar administration of BDNF and aFGF on regrowth and maintenance of afferent vs. efferent processes.

\section{MATERIALS AND METHODS Study groups and design}

Studies were performed in pigmented 250-350-g guinea pigs of both genders from Elm Hill Breeding Labs (Chelmsford, MA). Animals were housed in facilities accredited by the Association for Assessment and Accreditation of Laboratory Animal Care International, with free access to food and water throughout the duration of the experiment. Veterinary care and animal husbandry were provided by the Unit for Laboratory Animal Medicine at the University of Michigan, and all protocols were approved by the University Committee for the Use and Care of Animals at the University of Michigan. Experiments were performed in accordance with the guidelines of the National Institutes of Health Guide for the care and use of laboratory animals (NIH Publications No. 80-23, revised 1978). A concerted effort was made to minimize both the number of animals used and the suffering of subjects involved in the study.

Normal hearing by baseline acoustic auditory brainstem response (aABR 1) recording was necessary for inclusion in the study. Animals were then randomly divided into eight groups (Fig. 1). Group 1 animals were nontreated, normal hearing controls. Groups 2-8 were systemically deafened with kanamycin $(450 \mathrm{mg} / \mathrm{kg}) \mathrm{SQ}$ followed (2 hours later) with ethacrynic acid $(60 \mathrm{mg} / \mathrm{kg})$. Deafness was confirmed by acoustic auditory brainstem response (aABR 2) to a click stimulus (Miller et al., 2007) with a 60-dB SPL threshold shift necessary for continued inclusion (groups 2 and 4 were tested 3 days following deafening; groups 3 and 5-8 were tested 5-7 days following deafening). Groups 2, 3, and 6 received no further treatment after they were deafened and were assessed 3 , 7 , and 21 days following deafening, respectively. Two groups (groups 4 and 7) received NTF treatment. Group 4 received 26 days of chronic intrascalar infusion of $\mathrm{BDNF}$ $(100 \mu \mathrm{g} / \mathrm{ml})$ and aFGF $(50 \mathrm{ng} / \mathrm{ml})$ in one ear from a miniosmotic pump with a cannula into scala tympani (as in Brown et al., 1993; Prieskorn and Miller, 2000), with treatment starting 3 days following deafening (PD3 + 


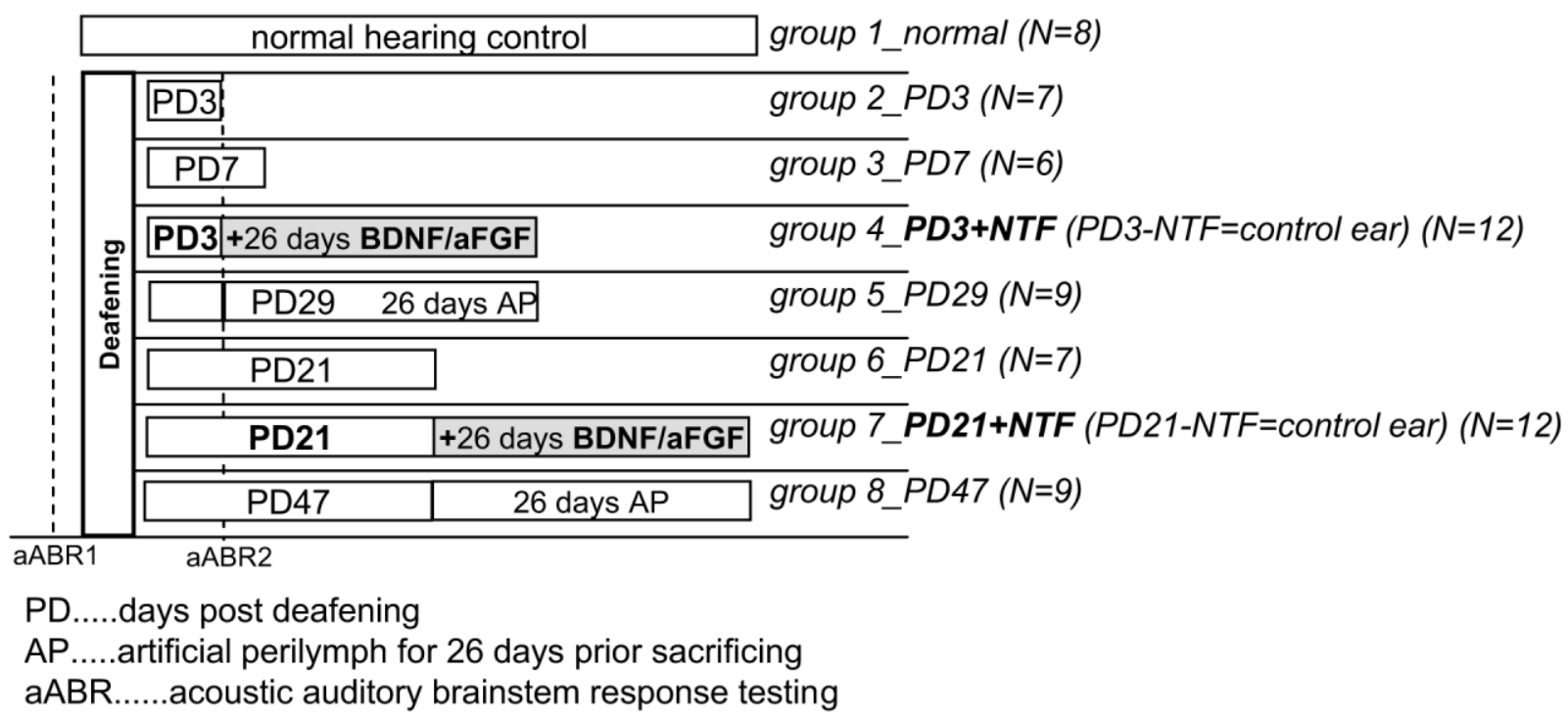

Fig. 1. Animal groups used in this study. aABR1 confirmed normal hearing prior to deafening procedure; aABR2 confirmed a $60-\mathrm{dB}$ shift in threshold after kanamycin/ethacrynic acid deafening. Group 4 (immediate treatment, PD3 + NTF) and group 7 (delayed treatment, $\mathrm{PD} 21+\mathrm{NTF})$ received BDNF and aFGF into one ear. The contralat-

NTF) and assessment 29 days after deafening. Group 7 received 26 days of chronic intrascalar infusion of BDNF and $\mathrm{aFGF}$, with treatment starting 21 days following deafening (PD21 + BDNF) and hence assessment 47 days after deafening. The unimplanted ears in groups 4 (PD3 NTF) and 7 (PD21 - NTF) without NTF treatment served as a control to assess contralateral effects of the drugs. Groups 5 and 8 received 26 days of chronic intrascalar infusion of artificial perilymph (AP) 3 days and 21 days postdeafening and were assessed 29 and 47 days postdeafening. This experimental setup and the total amount of animals (N) used in each group is summarized in Figure 1.

\section{Assessments: coimmunolabeling of efferent and afferent processes for confocal microscopy}

Three guinea pigs from each group were processed for coimmunolabeling of afferent and efferent processes in the organ of Corti. Guinea pigs were heavily anesthetized with chloral hydrate and perfused through the left ventricle with phosphate buffer followed by $4 \%$ paraformaldehyde in phosphate buffer. Temporal bones were carefully removed, and cochleae then received local intrascalar fixation with the same fixative followed by rinsing in buffer. The otic capsule of the cochleae was removed in $0.1 \mathrm{M}$ phosphate-buffered saline (PBS; pH 7.4) using preparation needles and watchmaker's tweezers. The remaining cochleae were decalcified in $10 \%$ ethylenedinitrilotetraacetic acid disodium salt dihydrate (EDTA; Titriplex III; Merck, Darmstadt, Germany) in PBS, pH 7.4, for 3-4 weeks, followed by rinsing in PBS. The stria vascularis, Reissner's membrane, and most bony parts near the modiolus were removed using a curved Vannas microiris scissor. The turns of the cochlea were cut into half coils and transferred to small vials with plastic seals containing PBS. eral ears (PD3 - NTF and PD21 - NTF) received no treatment. PD, days postdeafening; AP, artificial perilymph for 26 days prior to sacrifice; aABR, acoustic auditory brainstem response; $N$, total amount of animals used in each group. [Color figure can be viewed in the online issue, which is available at www.interscience.wiley.com]

Specimens were then rinsed several times in PBS with $0.3 \%$ Triton X-100 and 30\% normal donkey serum (NDS) to reduce nonspecific binding. The half coils were then incubated in a mixture of antisynaptophysin (Sigma, St. Louis, MO; S 5768; 1:1,000; as a marker for efferents) and antiparvalbumin (SWant, Bellinzona, Switzerland; PVG$214 ; 1: 7,000$; as a marker for afferent processes) in PBS with $1 \%$ NDS and $0.3 \%$ Triton $\mathrm{X}-100$ for 2 days at $4^{\circ} \mathrm{C}$ and then 1 hour at RT. The monoclonal antisynaptophysin antibody (IgG1 isotype) is derived from a hybridoma (clone SVP-38) produced by fusion of mouse myeloma and splenocytes mouse immunized with a synaptosome preparation from rat retina and recognizes the $38-\mathrm{kDa}$ band on Western blot with rat brain extracts (manufacturer's information). The polyclonal antiparvalbumin antiserum was generated in goat against rat muscle parvalbumin and recognizes the $12-\mathrm{kDa}$ band on Western blots with cerebellar extracts in rat and guinea pigs (information kindly provided by Prof. Marco Celio, Division of Anatomy, University of Fribourg).

Cochleae incubated without primary antisera or with antisera preabsorbed with the synthetic synaptophysin peptide (10 $\mu \mathrm{M}, 24$ hours, $\left.4^{\circ} \mathrm{C}\right)$ served as controls in each experiment. The polyclonal antiparvalbumin antibody produced a staining pattern in sections of the organ of Corti and spiral ganglion of normal hearing guinea pigs that is identical to that previously reported (Eybalin and Ripoll, 1990; Soto-Prior et al., 1995; Pack and Slepecky, 1995). After rinsing in PBS (five times, 10 minutes each), the specimens were then processed with a mixture of the secondary antibodies [Cy5 donkey anti-mouse IgG; 1:800; code 715-175-150 from Jackson Immunoresearch (West Grove, PA) and Alexa Fluor 488 donkey anti-goat IgG 1:2,000; catalog No. A11055 from Molecular Probes (Eugene, OR)] in PBS containing 1\% NDS for 2 hours at RT in a dark chamber. Based on immunoelectrophoresis, Cy5 
donkey anti-mouse antibody reacts with the heavy chains on mouse IgG and with light chains common to most mouse immunoglobulins. No antibody was detected against nonimmunoglobulin. Alexa Fluor 488 donkey antigoat reacts with IgG heavy chains and all classes of immunoglobulin light chains from goat (both manufacturer's information). After rinsing again in PBS (five times, 10 minutes each) the whole-mount preparations were covered with Vectashield Mounting Medium (Vector Laboratories, Burlingame, CA). Corresponding cochlear turns of each ear from the same animal were exposed simultaneously to the same solutions to ensure equal treatment of NTF-treated and untreated contralateral ears.

Sections were analyzed on a Zeiss LSM 510 Meta laser scanning microscope (LSM) with software release 3.2. Frame size was set as predefined number of pixels $(1,024 \times 1,024$ pixels are used), and color depth was set to eight bit. Z-stacks through the whole organ of Corti were made with a Zeiss PlanNeofluar $\times 40,1.3$, DIC using the 488-nm line of an argon/krypton $30-\mathrm{mW}$ laser set to $21 \%$ output power for excitation of Alexa 488 and a $5-\mathrm{mW}$ helium neon laser $633 \mathrm{~nm}$ (80\% output power) for excitation of Cy5. Confocal stacks were acquired in single-track line scan mode unidirectional, using separate channels. An NTF 545 beam splitter and 505-550-nm bandpass filter were used for Alexa 488 detection and a 650-nm longpass filter for $\mathrm{Cy} 5$, respectively. Additionally the transmitted light channel was recorded to visualize nonimmunostained tissue structures. Pinholes were set to 1 airy units, detector gain, and amplifier offset was adjusted using the range indicator function of the Zeiss software. Amplifier gain was set to 1, and line scans were set to four times mean average with a scan speed of $1.6 \mu$ sec pixel time. Corresponding cochlear turns of the same animal were recorded sequentially with the identical microscope settings. For visualization, xy-projections of the z-series confocal stacks into one plane were performed with the LSM510 software. Red and green fluorescence was merged with the Zeiss LSM software and exported as TIF files. Conversion into magenta-green was performed with Adobe Photoshop CS by coping the red channel into the blue channel of the RGB image.

\section{Assessments: image analysis of coimmunolabeling of efferent and afferent processes for confocal microscopy}

Parvalbumin immunoreactivity was semiquantitatively assessed by using the image-analysis software Image Pro 6.0 (Media Cybernetics, Silver Spring, MD) with 3D constructor extension package (AMD Opteron workstation; 8 GB RAM, Nvidia 6800 Ultra graphic board, Windows XP professional 64-bit edition). Alexa 488 fluorescence was extracted as a gray image stack, subsampled 2:2:1 (x:y:z) and filtered with a LoPass $3 \times 3 \times 3$ filter. No other prior filtering or deconvolution was done with the data sets. Isosurface values were defined interactively for one specimen and set as default for the contralateral ear. Isosurfaces and volumes were generated using the automatic close-edge function of the software and exported to a $\mathrm{Mi}$ crosoft Excel datasheet. Organ of Corti length (OL) was measured at the level of the inner spiral bundle orientating at synaptophysin immunoreactivity. The ratio of volume of parvalbumin immunoreactivity $\left(\Sigma V_{\text {parv }}\right)$ to $\mathrm{OL}$ per image stack served as a comparative measure. The sum of
$\Sigma \mathrm{V}_{\text {parv }} / \mathrm{OL}$ of $1 \mathrm{a}$ and $1 \mathrm{~b}$ half turns was used to compare ears treated with BDNF/aFGF and contralateral untreated ears. Additionally, the amounts of parvalbuminpositive puncta per $100 \mu \mathrm{m}$ organ of Corti length are given. Analysis of variance between BDNF/aFGF and contralateral untreated ears within the same animal was tested with Student's $t$-test to find statistical significant differences in mean $\Sigma \mathrm{V}_{\text {parv }} / \mathrm{OL}$ in the basal turn.

This evaluation allows us only semiquantitatively to compare the two ears of the same animal, because the setups of preparation (use of the same washing, blocking and antibody solutions, and incubation conditions) and acquisition (identical microscope settings) were equal. Specimens prepared and assessed on another day with minimal diverging preparation and acquisition conditions cannot be compared with fluorescence labeling. Photobleaching during image acquisition was assumed to be approximately the same for corresponding cochlear turns. Only $1 \mathrm{a}$ and $1 \mathrm{~b}$ half-turns excluding the hook region of the sensory epithelium were used for this assessment.

\section{Assessments: preembedding synaptophysin and parvalbumin immunoperoxidase staining for light and electron microscopic assessment}

Three to seven animals from each group (groups 4, 5, 7, $8=$ six or seven animals; groups $1-3,6=$ three or four animals) were processed for preembedding immunoperoxidase staining for synaptophysin and parvalbumin with assessments at the light and electron microscopic levels. Animals received vascular perfusion as described above but with fixative containing $4 \%$ paraformaldehyde and $0.5 \%$ glutaraldehyde in cacodylate buffer. Otic capsule, Reissner's membrane, and stria vascularis were removed. Decalcification with EDTA was performed as described above. After being thoroughly washed in PBS, cochleae were microdissected perpendicular to the radial plane into hook region, basal turn, second turn, and apex, followed by radial bisection paramodiolar. (The half-turns containing the modiolus of these specimen were also used for assessment of spiral ganglion neurons; see below.) Specimens were rinsed either in 10\% normal goat [for synaptophysinlike immunocytochemistry (ICC)]: efferent marker, monoclonal, generated in mouse; Sigma; S 5768) or donkey serum (for parvalbumin-like ICC: afferent marker, polyclonal, generated in goat; SWant; PVG-214), both containing an additional $1 \%$ bovine serum albumin (BSA; lyophilized albumin bovine fraction V; Serva, Heidelberg, Germany) to reduce nonspecific binding sites and $0.25 \%$ Triton X-100 (Roche 789704) in 50 mM Tris-HCl-buffered saline (TBS). The primary antibody was diluted 1:1,000 for antisynaptophysin and 1:7,000 for antiparvalbumin (for description of antibodies see above), and cochleae were incubated for $2-3$ days at $4^{\circ} \mathrm{C}$, then for 2 hours at room temperature. Detection of primary antibodies was performed with suitable Vectastain Elite ABC kits (Vector, Burlingame, CA). After the specimens were rinsed five times in TBS, a peroxidase-conjugated antibody raised against the primary antibodies (biotinylated anti-mouse made in horse from PK-6102 kit or anti-goat made in rabbit from PK-6105 kit; IgG, 1:200) was applied for detection followed by an avidin horseradish peroxidase complex (1:75 from Vectastain Elite ABC kit) according to the manufacturer's protocol. Peroxidase activity was revealed 
by using 0.05\% 3,3'-diaminobenzidine (DAB; Sigma, Munich, Germany) as a chromogen and $0.04 \%$ perhydrol as substrate $\left(\mathrm{H}_{2} \mathrm{O}_{2} 30 \%\right.$; Merck, Darmstadt, Germany) with cobalt chloride to intensify staining.

Specimens were then processed according to standard technique for transmission electron microscopy (TEM). Whole mounts were fixed in Karnovsky's fixative (5\% glutaraldehyde and 4\% paraformaldehyde in cacodylate buffer) overnight and then received four 15-minute washes in $0.1 \mathrm{M}$ cacodylate buffer, followed by postfixation with $1 \%$ osmium tetraoxide in $0.05 \mathrm{M}$ cacodylate buffer for 1 hour (at $4^{\circ} \mathrm{C}$ ). Excessive osmium tetraoxide was removed by rinsing the specimens four times (15 minutes each) in $0.1 \mathrm{M}$ cacodylate buffer. The specimens were then dehydrated in a series of ethanols $(2 \times 70 \%$ ethanol each 15 minutes, $2 \times 96 \%$ ethanol each 15 minutes, $2 \times 100 \%$ ethanol each 15 minutes). Propylene oxide was used as an intermedium $(2 \times 15$ minutes $)$, prior to incubation in a dilution of liquid epoxy resin (according to Spurr, 1969) and propylene oxide in equal shares overnight in closed vials. On the next day, the mixture was replaced by $100 \%$ epoxy resin and changed twice (1 hour each in a vacuum chamber). Specimens were then transferred to an embedding mold, labeled, and placed in a vacuum chamber for an additional 1 hour. After checking the orientation of the half-coils under a stereomicroscope, the specimens were transferred to an incubation chamber at $60^{\circ} \mathrm{C}$ for 48 hours to increase the polymerization of the epoxy resin.

One-micrometer sections were cut on a Leica Ultracut microtome, lightly stained with toluidine blue at $60^{\circ} \mathrm{C}$, and then examined using a light microscope. Radial sections were used for assessment of immunoperoxidase staining; in the midmodiolar plane, these sections were also used for SGN assessments. Specimens for TEM were trimmed and ultrathin sections $(90 \mathrm{~nm})$ acquired and transferred to Formvar-coated slot grids. These were examined with a Zeiss Libra 120 transmission electron microscope at $80 \mathrm{kV}$ (Division of Ultrastructural Research and Evolutionary Biology, Institute of Zoology, Leopold Franzens University, Innsbruck).

\section{Assessments: SGN and peripheral nerve fibers}

The portion of the cochlear half-turn containing the modiolus of the immunoperoxidase-embedded tissues (see above) was used for SGN assessment. One-micrometerthick sections in a paramodiolar plane were acquired with a Leica Ultracut microtome. Once a midmodiolar plane was reached, three $1-\mu \mathrm{m}$ sections were acquired at $30-\mu \mathrm{m}$ intervals, mounted on glass slides, and Nissl stained with toluidine blue at $60^{\circ} \mathrm{C}$ on a hotplate.

Three slides per cochlear turn were therefore used for each of the three to seven animals in each group. Two profiles per cochlear turn through Rosenthal's canal were assessed for each slide (two for first turn, two for second turn, two for upper turn). SGN in the hook region and apical end were excluded. Digital images of the entire profile were acquired in Image-Pro 6.0 (Media Cybernetics) linked to a 3-CCD color video camera (Sony DXC950P) and an Olympus BX50 light microscope. The outline of the Rosenthal's canal profile was then traced, and the area, excluding the area of blood vessels, measured. Each SGN was counted. The SGN density expressed as the density of SGN for an area of square millimeters was then determined. The arithmetic mean of longest and shortest diameter per SGN of the 10 largest cells per Rosenthal's canal view was determined. The mean density and mean diameter of SGN was assessed for each profile and displayed as box plot diagrams. The box contains $50 \%$ of the data; the upper edge of the box indicates the 75th percentile of the data set, and the lower hinge indicates the 25 th percentile. The line in the box points to the median value of the data; "whiskers" indicate the minimum and maximum data values, excluding suspected outliners (not shown).

Analysis of variance between animal groups on spiral ganglion density data were tested with a one-way ANOVA, and post hoc Student-Newman-Keuls test served to find statistical significant differences in the mean density. Differences associated with $P$ values less than 0.05 were considered to be statistically significant and are displayed in the diagrams as horizontal (no significant difference between selected animal groups) and vertical bars (statistically significant difference between selected animal groups). Tangential sectioning of the OSL gave a cross-sectional view of most peripheral nerve fibers to estimate nerve fiber loss and effect of NTF treatment. Sections at the level of the distal end of the spiral limbus were used.

\section{Assessments: electron microscopic assessment}

Two animals of each NTF treated group and two normal hearing animals were fixed with Karnovsky's solution (4\% paraformaldehyde and 5\% glutaraldehyde in $0.1 \mathrm{M}$ cacodylate buffer, $\mathrm{pH}$ 7.3-7.4) and processed for standard TEM as described above. This ensured optimal fixation quality for ultrastructure. The myelin layers of 20 type I neurons of each Karnovsky's-fixed temporal bone were counted in the basal turn to detect demyelination. Adjustments to brightness and contrast of light and electron micrographs were performed in Adobe Photoshop CS, and micrographs were stored as uncompressed eight-bit TIF files.

\section{RESULTS \\ Hair cell loss and organ of Corti scar formation}

Deafening with ototoxic drugs (kanamycin and ethacrynic acid) was effective in inducing loss of IHC and $\mathrm{OHC}$, with resulting scar formation in the sensory epithelium (outer hair cells) replacing the lost hair cells. There was a base-to-apex gradient in the thickness of the scar formations in all deafened animals (not shown) and a change in the appearance of the scar over time following deafening (Fig. 2), consistent with the literature (Hawkins and Engstroem, 1964; Johnsson and Hawkins, 1976; Bohne, 1977; Nadol, 1977; Raphael and Altschuler, 1991, 1992). In the basal turn at 3 days following deafening (Fig. $2 \mathrm{~B})$, no OHC and only few IHC or IHC remnants were present (two animals with IHC survival were excluded from the study). At 7 days following deafening (Fig. 2C), supporting cells such as tectal cells, inner and outer sulcus cells, or collapsed pillar cells were still distinguishable. At 21 and 29 days following deafening, in $50 \%$ of animals there was only a single layer of cells remaining in the basal portion of the first turn, whereas, more apically in the first turn, there was thicker scar formation with dis- 


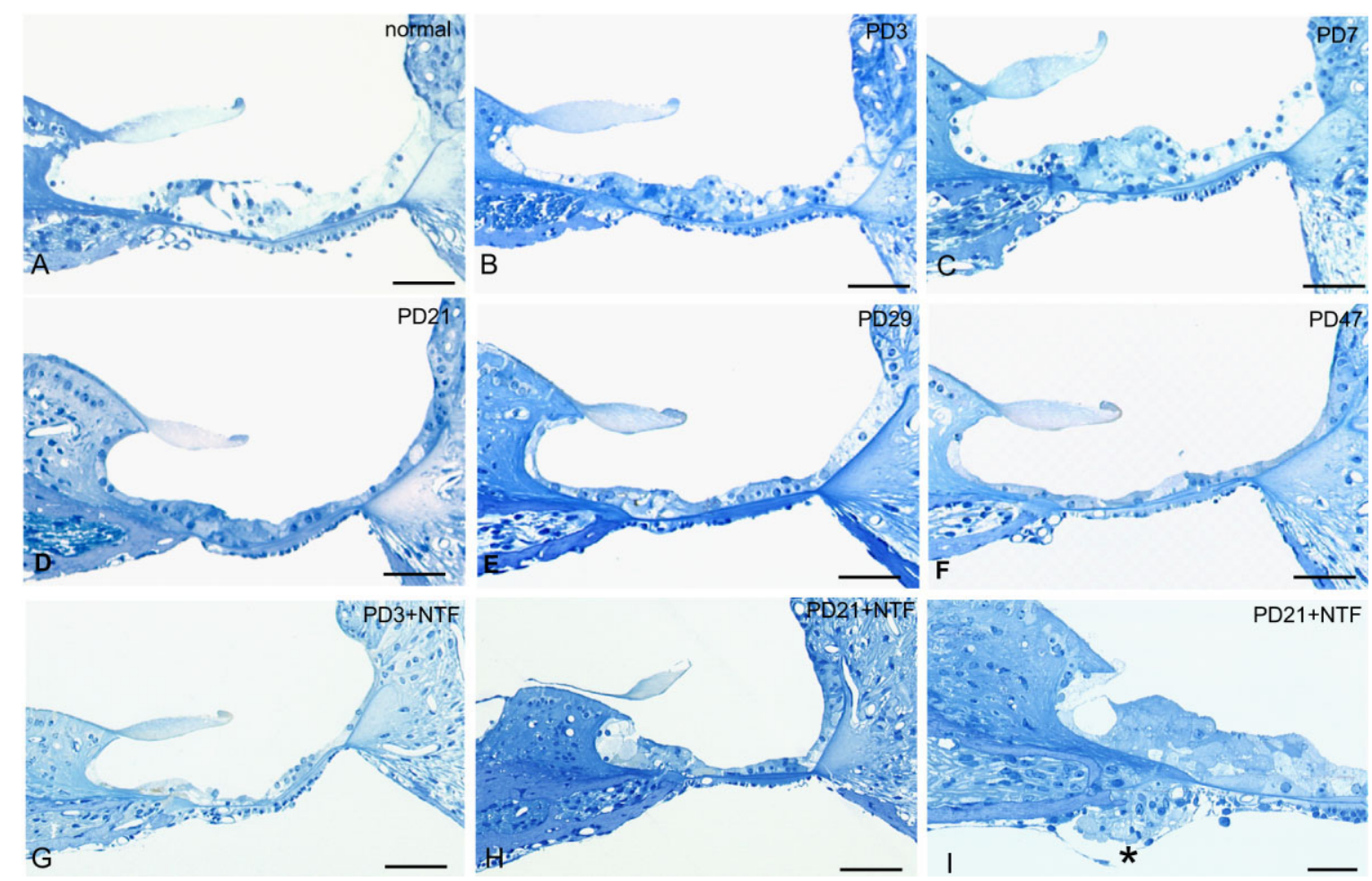

Fig. 2. A-I: Scar formation of the sensory organ postdeafening in the lower basal turn (1a). Deafening leads to a rapid loss of hair cells 3 days postdeafening (PD3). Until PD7, the scar formations are rather thick and contain some distinguishable supporting cells. Sensory epithelial remnants flatten 21 and 29 days postdeafening and are re- duced to a single cell layer in PD47 animals. Immediate and delayed NTF treatment can lead to both a fairly thin epithelial layer $(\mathrm{G}, \mathrm{H})$ and thick scars with new tissue formation close to the habenula perforata (I, asterisk). Scale bars $=50 \mu \mathrm{m}$. [Color figure can be viewed in the online issue, which is available at www.interscience.wiley.com] tinct supporting cells, comparable to the 7-dayspostdeafening animal group. The other $50 \%$ of animals had an intermediate thickness of scar tissue (Fig. 2D,E) across the whole basal turn. By 47 days following deafening, sensory epithelium of the scar was reduced to only one flattened layer of cells (Fig. 2F) in all nontreated animals.

In ears treated with neurotrophins (Fig. 2G-I), the scar formations never reached the single layer of cells seen in untreated animals. Most animals showed a thick scar formation with readily distinguishable supporting cells in the basal and higher turns in the NTF-treated ears. In some animals, new tissue formation bulging into the scala tympani at the level of the habenula perforata could be observed from lower basal (Fig. 2I) to upper middle turn, seen in both group 4 (receiving NTFs at either 3 days following deafening; PD3 + NTF) and group 7 (receiving NTFs at 21 days following deafening; PD21 + NTF) on their NTF-treated ears. Contralateral untreated ears (PD3 - NTF, PD21 - NTF) showed morphology comparable to that of untreated animals (PD29, PD47).

\section{Peripheral nerve fiber loss}

As hair cells are lost, peripheral nerve fibers degenerate over time (Fig. 3A-C), as seen in tangential sections. At 3 days following deafening, there remained a high density of myelinated processes in the osseous spiral lamina (Fig. $3 \mathrm{~A})$ that gradually decreases to fewer nerve fibers 47 days postdeafening (Fig. 3C). Both immediate and delayed NTF treatment (Fig. 3D,E) not only prevents this degeneration but also leads to a regrowth of fibers into the scala tympani. In two animals with some fibrous tissue in 1a turn, this outgrowth was seen more frequently (Fig. 3D), and nerve fibers in the scala tympani make up a myelin layer. The cells between myelinated and unmyelinated nerve fibers shared the morphology of Schwann cells at the EM level (Fig. 3E).

\section{Parvalbumin immunolabeling in normal hearing, untreated animals}

There was parvalbumin immunolabeling of afferent peripheral processes and IHC in the cochlea of normal hearing animals, consistent with the staining pattern in the cochlea from the literature (Eybalin and Ripoll, 1990; Soto-Prior et al., 1995; Pack and Slepecky, 1995). In plastic cross-sections through immunoperoxidase-stained surface preparations (Fig. 4), there was parvalbumin immunostaining of afferent peripheral processes streaming through the osseous spiral lamina via the habenula perforata (Fig. 4A,B), forming rosettes of terminals under IHC. IHC (Fig. 4A) were also parvalbumin immunolabeled as well as basal cells in the stria vascularis, which distinguishes them from the melanin granules in the intermediate cells layer (Fig. 4D). The afferent nerve endings beneath $\mathrm{OHC}$ and basal tunnel crossing fibers were not immunolabeled with parvalbumin, indicating that the processes of type II SGN innervating OHC were not parvalbumin positive. Whereas type I SGN and the myelinated nerve fibers might be expected to be immunolabeled, there 


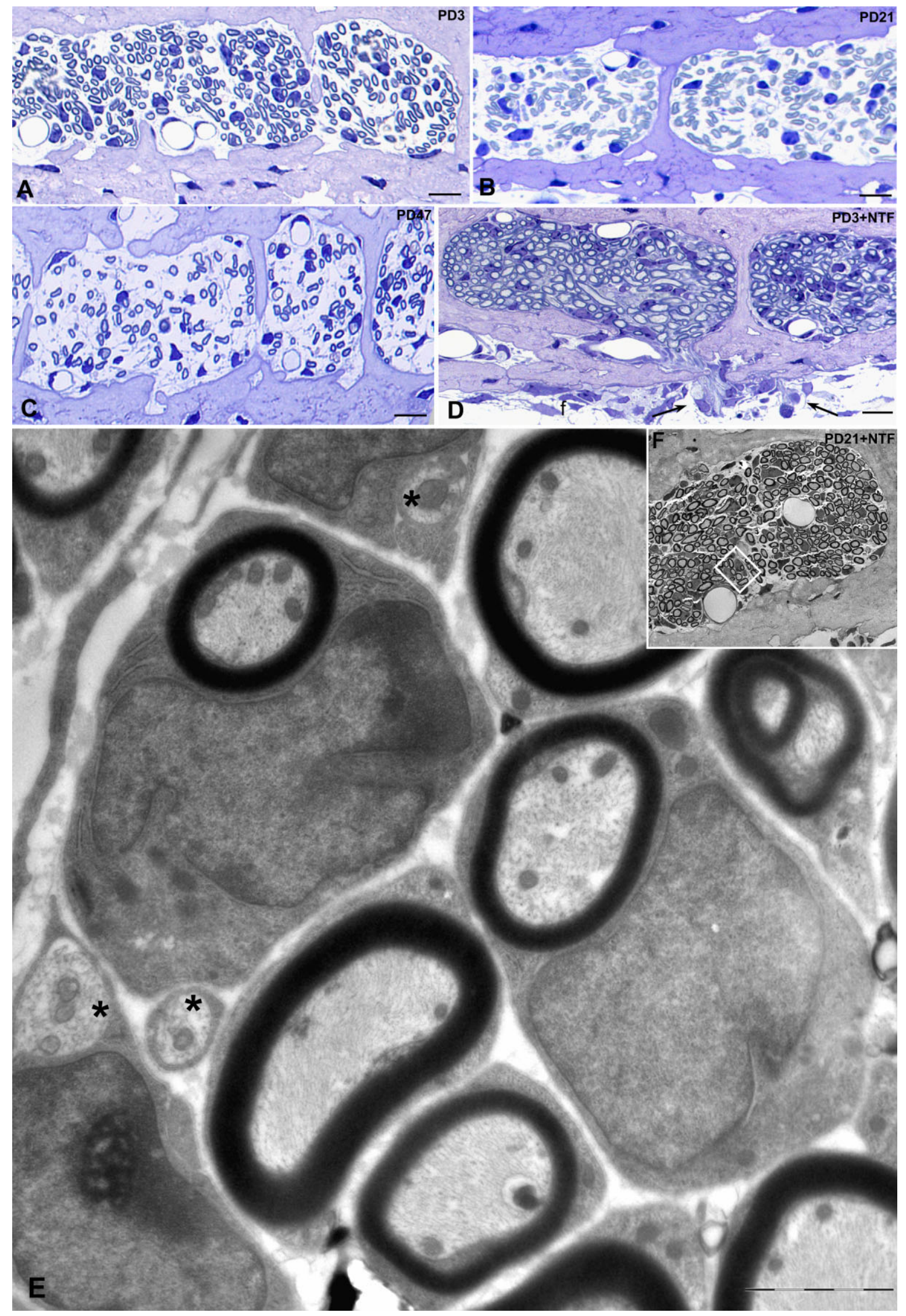

Fig. 3. Peripheral nerve fiber loss and neurotrophic treatment in the lower basal turn. A,B,C,D are semithin sections; E,F are electron micrographs; framed area in Fig. F represents the more highly magnified view in $\mathrm{E}$. A considerable loss of myelinated nerve fibers occurs between 3 and 47 days postdeafening (A-C). NTF-treated animals $(\mathrm{D}, \mathrm{E}, \mathrm{F})$ show high nerve fiber densities and outgrowth of fibers into the scala tympani (D, arrows) that contains some fibrous tissue (D-F). Cells between nerve fibers share the morphology of Schwann cells (E) and ensheath myelinated as well as unmyelinated (asterisks) nerve fibers. Scale bars $=10 \mu \mathrm{m}$. [Color figure can be viewed in the online issue, which is available at www.interscience.wiley.com] 

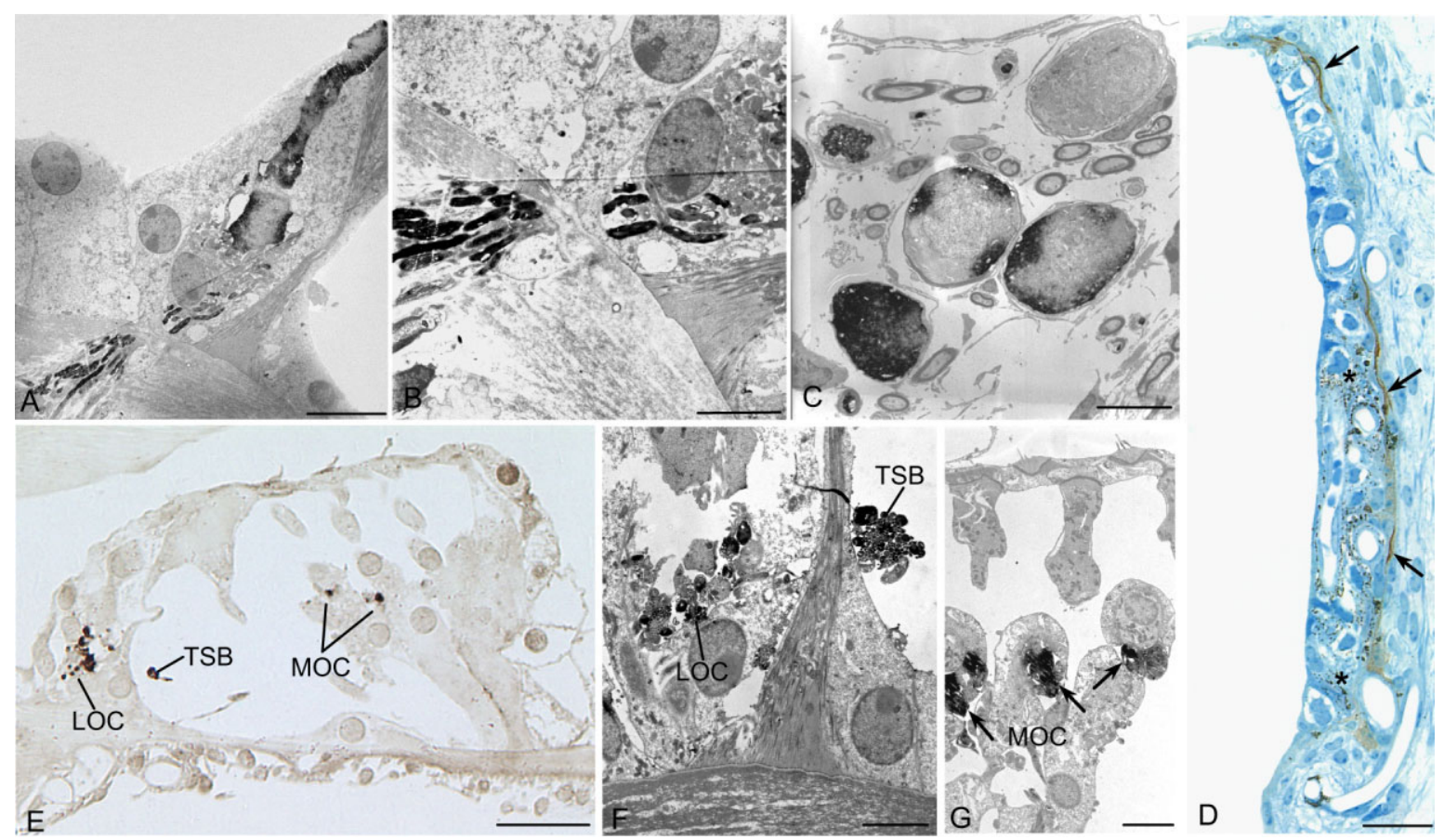

Fig. 4. Parvalbumin and synaptophysin immunoreactivity in the normal guinea pig cochlea. A-C,F,G are electron micrographs; D,E are semithin sections (E not counterstained). Parvalbumin LI stains afferent processes as they loose their myelin sheet close to habenula perforata and their target, the IHC (A,B). SGN are also immunopositive (C), and antibody penetration is impeded by the myelin sheet. Basal cells in the stria vascularis show immunoreactivity for parvalbumin (D) that distinguishes them from the melanin granules in the intermediate cell layer (asterisks). Synaptophysin ICC stains medial (MOC) as well as lateral (LOC) olivocochlear nerve fibers (E), which are efferents below the IHC (lateral efferents), the tunnel spiral bundle (TSB), and fibers originating from the medial olivary complex, especially the medial efferent terminals below the $\mathrm{OHC}$ (G, arrows). Scale bars $=10 \mu \mathrm{m}$ in A,C; $5 \mu \mathrm{m}$ in B,F,G; $20 \mu \mathrm{m}$ in $\mathrm{D} ; 25 \mu \mathrm{m}$ in $\mathrm{E}$ was only scattered immunolabeling, with most SGN unlabeled. This is likely methodological, a consequence of a lack of antibody access to the modiolus as well as the thick myelin sheet around SGN and their nerve fibers, which can prevent sufficient penetration of antibodies when using preembedding staining on whole cochleae.

The typical pattern of parvalbumin immunolabeling was also seen with immunofluorescent labeling of surface preparations (Fig. 5A), where there was immunolabeling of IHC and labeling of afferent processes in form of puncta at IHC bases. There was no immunolabeling in the $\mathrm{OHC}$ region.

No parvalbumin-immunostained fibers, terminals, cells, or structures coimmunolabeled with synaptophysin in surface preparations (parvalbumin green, synaptophysin magenta; colabeling if present would be white) wee seen with confocal microscopy (Fig. 5A). This confirms the selectivity of synaptophysin and parvalbumin as markers for differentiating efferent vs. afferent fibers and terminals. In control preparations of inner ears without primary antisera or antisera preabsorbed with the synthetic synaptophysin peptide, no synaptophysin- or parvalbumin-like immunoreactivity was observed on surface preparations or in semi- and ultrathin plastic sections.

\section{Synaptophysin immunolabeling in normal hearing, untreated animals}

There was synaptophysin immunolabeling of both medial and lateral efferent fibers and terminals in the organ of Corti of normal hearing animals, consistent with the staining pattern reported in the literature (Gil-Loyzaga and Pujol, 1988; Nadol et al., 1993; Knipper et al., 1995; Simmons et al., 1996; Counter et al., 1997). In plastic cross-sections through immunoperoxidase-stained surface preparations (Fig. 4E-G), synaptophysin-immunostained lateral efferent fibers and terminals can be seen in the inner spiral bundle under IHC and in the tunnel spiral bundle (Fig. 4E,F), and medial efferent terminals at the $\mathrm{OHC}$ bases were also immunostained. In immunofluorescence-stained surface preparations viewed with the LSM (Fig. 5A), there was synaptophysin immunolabeling (red) of lateral efferents in the inner and tunnel spiral bundles and of medial efferents in tunnel crossing fibers and prominent puncta under OHC bases.

\section{Parvalbumin-synaptophysin-like immunoreactivity changes following deafening}

PD3. Surface preparations with synaptophysin (magenta) and parvalbumin (green) immunostaining revealed a loss of IHC and a decrease in afferent but not efferent processes at 3 days following deafening. There was a large decrease in parvalbumin-immunostained afferent processes and endings, with the greatest decrease in basal turns and less decrease in apical turns (Fig. 5B-D). An occasional parvalbumin-immunostained hair cell was observed in surface preparations (Fig. 5B-D), perhaps reflecting a delay in IHC death (because no IHC were ob- 

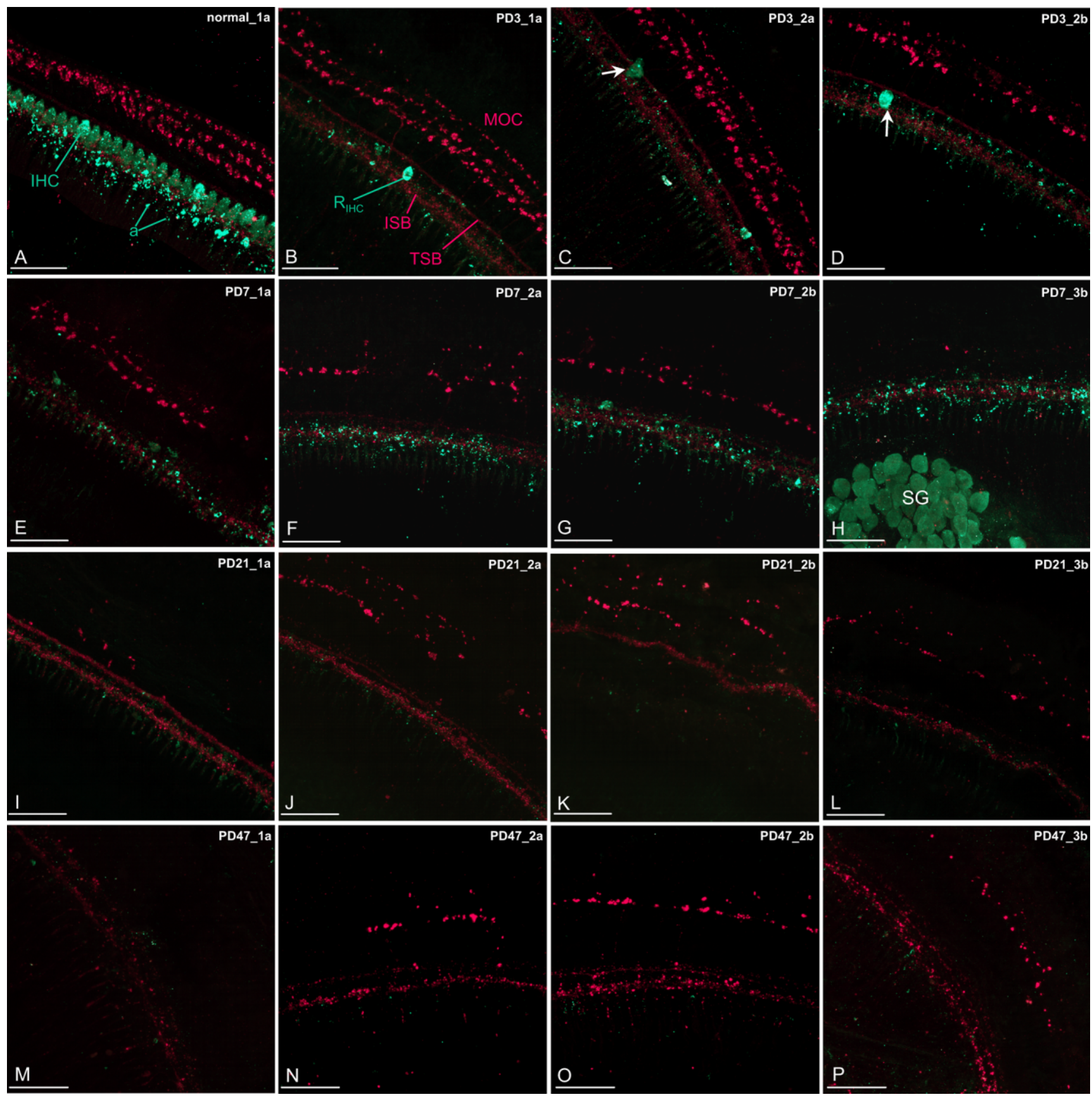

Fig. 5. A-P: Confocal microscopy of peripheral processes within the sensory epithelium: base-to-apex degeneration pattern. Parvalbumin LI green, synaptophysin LI magenta. Confocal projections in normal hearing animals (A) display IHC and more intense puncta representing afferent processes originating from type I neurons. Three rows of red puncta in the upper half of the picture represent efferent terminals innervating OHC. Lateral efferents are mostly hidden behind parvalbumin LI. PD3 cochleae (B) display the dramatic

loss of IHC, reduced to some IHC remnants $\left(\mathrm{R}_{\mathrm{IHC}}\right)$. OHC are com-

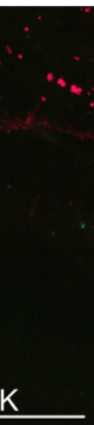

PD7_2b
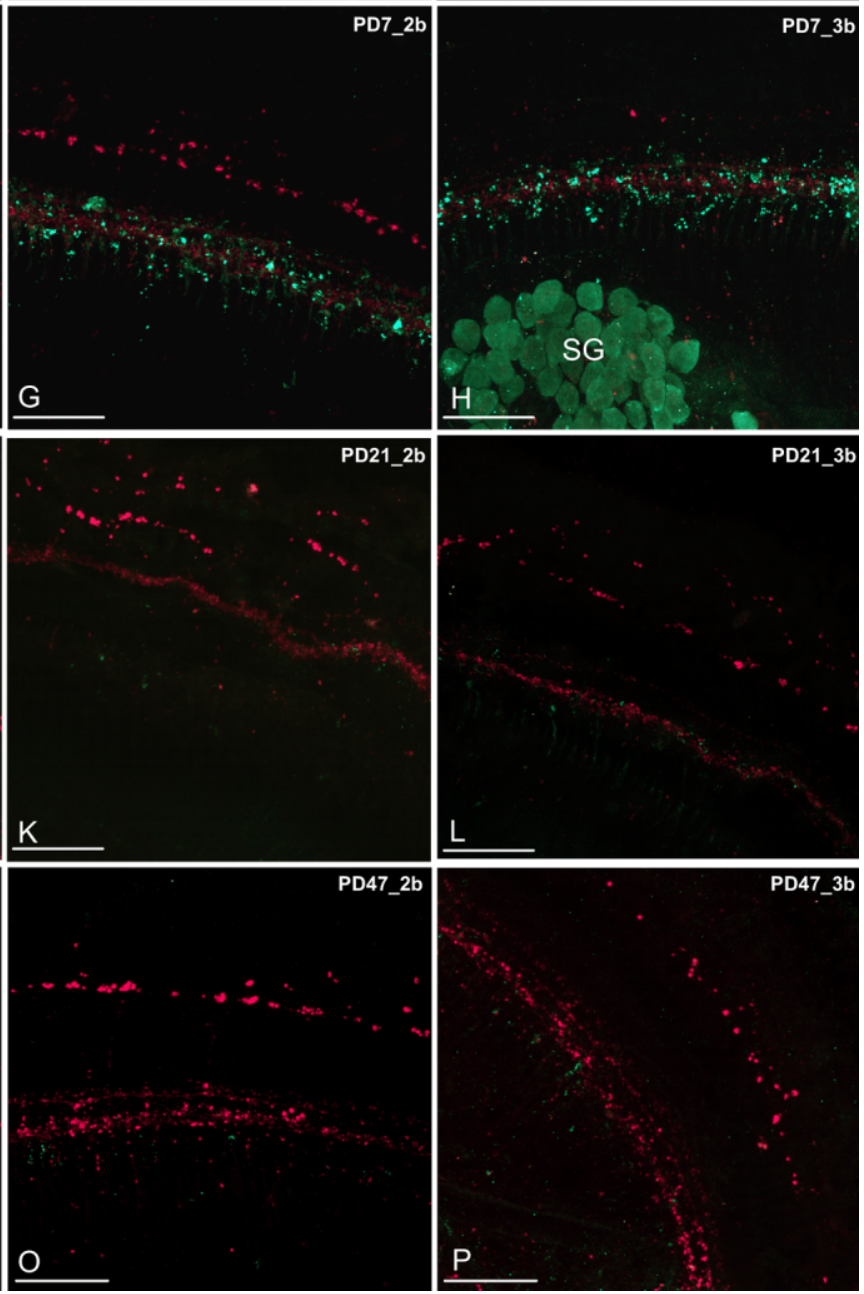

$\underline{\underline{L}}$

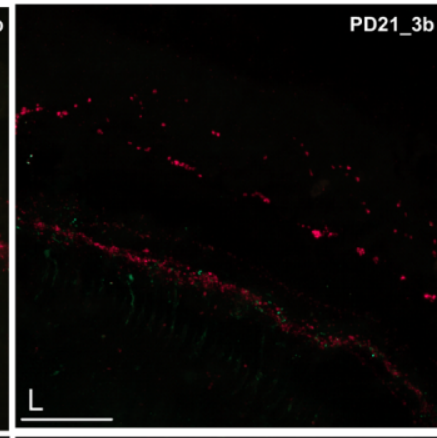

pletely lost (not stained), but medial efferent fibers still persist throughout all cochlear turns (C,D). Inner spiral bundle (ISB), tunnel spiral bundle (TSB), and MOC fibers are clearly distinguishable. PD7 animals reveal less parvalbumin LI in the lower basal (E) compared with higher turns $(\mathrm{F}, \mathrm{H})$. Typical efferent base-to-apex gradient displays almost complete loss of immunoreactivity of medial efferents in the lower basal turn in PD21 (I) and PD47 (M) animals and higher synaptophysin LI in more apical turns (J-L,NP). Scale bars $=50 \mu \mathrm{m}$.

served in later periods following deafening) or perhaps immunostaining of a remaining hair cell fragment. IHC remnants as well as IHC could occasionally been detected in semithin sections (not shown). There was no perceptible

loss of synaptophysin-immunostained medial or lateral efferents at 3 days following deafening (Fig. 5B-D), with no change in the appearance of the inner or tunnel spiral bundles (lateral efferents) and all three rows of immuno- 
stained medial efferent puncta remaining in the $\mathrm{OHC}$ region, even in the absence of OHC. As in the normal hearing cochlea, there was no colocalization of synaptophysin and parvalbumin in any cells, fibers, or structures, indicating that the deafening did not induce a change in phenotype and that synaptophysin and parvalbumin remain useful as selective markers.

$\boldsymbol{P D}$ \%. At 7 days following deafness, there was a continued decrease in parvalbumin-immunostained afferent processes and puncta, with the greatest loss in the basal turn (Fig. 5E-H). Synaptophysin-immunostained efferents remained relatively unaffected at 7 days following deafening in most animals, with normal-appearing inner and tunnel spiral bundles. Some loss of medial efferent puncta, particularly in the third row, was clearly visible.

PD21-PD47. Between 7 and 21 days following deafening, there was a dramatic loss of parvalbuminimmunostained afferent processes. At 21 days (Fig. 5I-L) and continuing at 29 (not shown) and 47 days (Fig. 5M-P) following deafening, parvalbumin immunostaining was almost completely absent across all turns of the cochlear spiral, except for rare and scattered fibers and puncta. No immunostained IHC were observed. At 21 days following deafening, the first obvious changes in synaptophysinimmunostained efferents were observed (Fig. 5I-L), predominantly in the basal turn. Although inner and tunnel spiral bundle had a normal appearance, there were only a few remaining medial efferent puncta in the $\mathrm{OHC}$ region, when present only in one row. It was not until 47 days following deafening (Fig. 5M-P) when immunolabeling of inner and tunnel spiral bundles diminished in most animals (more in base than in apex), and there was a large loss of medial efferent puncta across all turns.

In summary, after deafening with IHC loss, the afferent nerve fiber system degenerates rapidly, with a massive loss of afferent processes between 7 and 21 days postdeafening within the scar region. The lateral efferents are the most resistant, with little change at 21 days postdeafening, despite loss of their targets, and with immunostaining still present at 47 days following deafness, greater in more apical than more basal turns (Fig. 5I-P). Medial efferent terminals in the $\mathrm{OHC}$ region decrease at 21 days following deafening, greatest in the more basal turns (Fig. 5I-L), perhaps associated with the progression of the scar formation, with a flattened, thin epithelium in that position.

\section{Influence of BDNF/aFGF treatment on deafferentation-induced changes: immunofluorescent labeling of surface preparations}

There was a large increase in the parvalbumin immunostaining in animals receiving chronic intrascalar $\mathrm{BDNF} / \mathrm{aFGF}$ starting at 3 days following deafness, compared with untreated contralateral ears or untreated deafened animals. In immunostained surface preparations in both basal and more apical turns, there were numerous parvalbumin-immunostained puncta in treated animals compared with few in the untreated cochlea of the same animal (Fig. 6A-D, Table 1). A similar difference was seen when comparing animals receiving chronic intrascalar BDNF/aFGF starting at 21 days following deafness. Immunostained surface preparations showed numerous parvalbumin-immunostained puncta in treated animals compared with few in untreated ears of the same animals in both basal (Fig. 6E,F, Table 1) and more apical (Fig. $6 \mathrm{G}, \mathrm{H})$ turns.

Isosurface rendering of the data sets (Fig. 6 I-K) clearly displays distribution and size of immunoreactivity of the marker antibodies in normal and immediately- and delayed-NTF-treated animals. The significant effect of NTF is clearly demonstrated by semiquantification using isosurface rendering and volumetric evaluation of the entire basal turn (Table 1). BDNF/aFGF treatment provides a significant increase in parvalbumin immunostaining in treated vs. untreated ears of the same individual, with the increase ranging from two- to sevenfold.

NTF-treated animals show two to five times more parvalbumin-positive puncta along the basal turn than in the untreated contralateral ears (Table 1), and parvalbumin immunoreactivity is present more far distally in the scar region at sites where there are no afferents in normal hearing animals (Fig. 6K).

There are no quantitative or qualitative differences in immunofluorescent labeling of the efferent marker synaptophysin in the surface preparations in NTF-treated ears or contralateral untreated ears and no qualitative alterations compared with the control groups (PD29 and PD47). Thus the medial efferent system does not appear to be greatly influenced by NTF treatment.

\section{Influence of BDNF/aFGF treatment on deafferentation-induced changes: immunoperoxidase labeling in plastic sections (LM and TEM)}

Plastic sections through NTF-treated animals revealed parvalbumin immunostaining far distally and also proximally to the habenula perforata, at sites where no afferent nerve fibers are present in untreated and normal hearing animals. Positive staining was observed in the basal turn as far as inner sulcus cells adjacent to the tectorial membrane (Fig. 7A-C) and radially sprouting into the tectal cell area (Fig. 7B,C). At the transition from the bony columns that guide nerve fascicles from Rosenthal's canal to the habenula, an outgrowth of parvalbuminimmunostained afferent fibers into the scala tympani can be observed (Fig. 7B-D). In some animals, the amount of new tissue formation leads to a considerable bulge into the perilymphatic compartment (Fig. 7D). This was found only in the first and even more frequently in the second turn of the cochlear spiral. The neurotrophic effect on nerve fiber regrowth in the more apical region was less effective, although some animals also showed high levels of parvalbumin immunoreactivity (Fig. 7E) with equal staining pattern for parvalbumin observed in the basal turn. Nerve fibers were found in treated animals that progressed into the scala via canaliculi perforantes, small fenestration in the bone of Rosenthal's canal, and bony columns guiding nerve fibers to the osseous spiral lamina (Fig. 7F). These fibers reveal a myelin layer close to the spiral canal and within the bony canaliculi but with extreme swelling when entering the scala typani.

TEM assessment of ultrastructure confirmed immunoreactivity for parvalbumin within most regrown nerve fibers in the bulging tissue and fibers traveling between bone and mesothelial cells (Fig. 8A,B). Although fibers are surrounded by satellite cells (Fig. 8A), there are no myelin layers visible. Fibers in the habenula perforata showed higher levels of immunoreactivity in their axoplasm (Fig. 

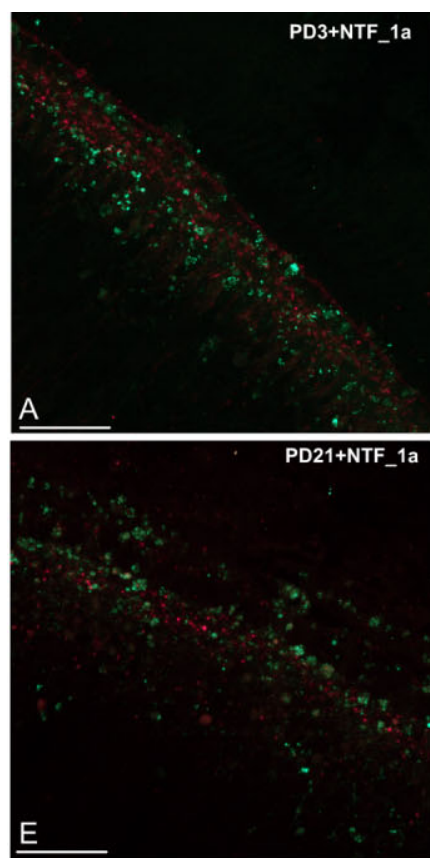
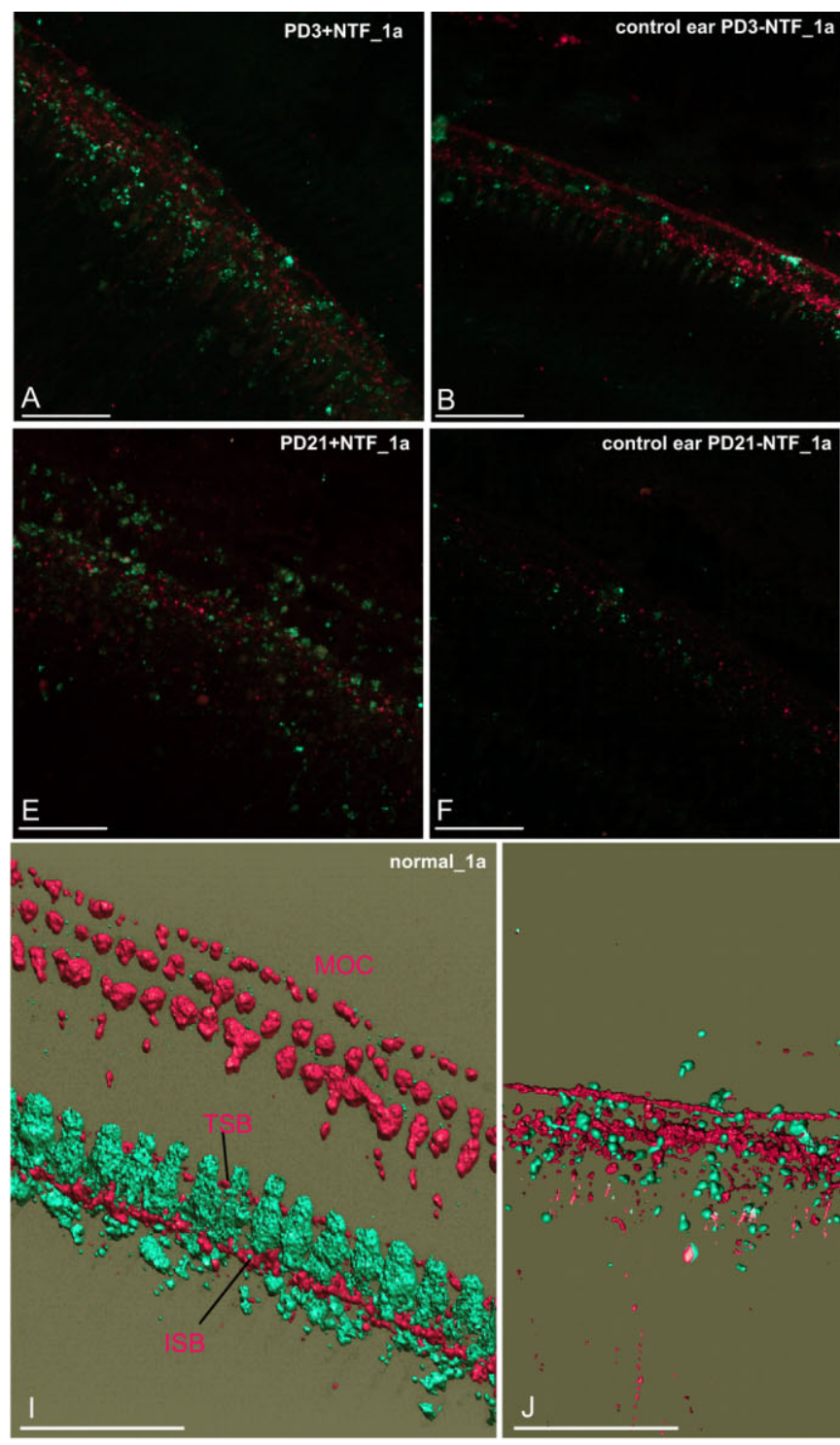
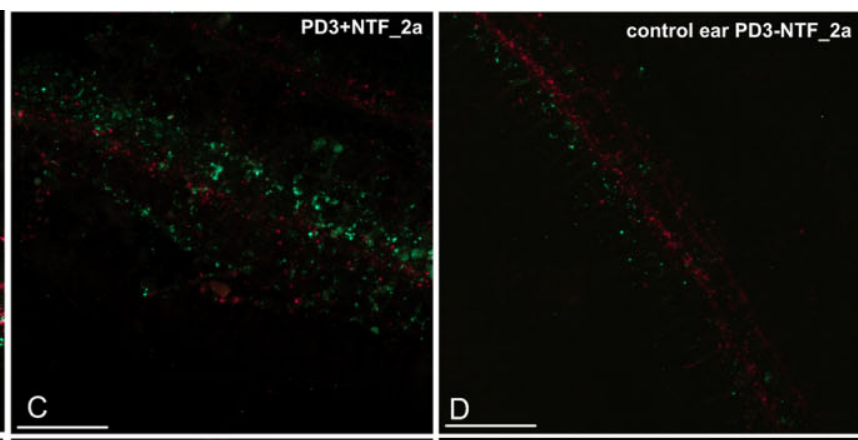

.
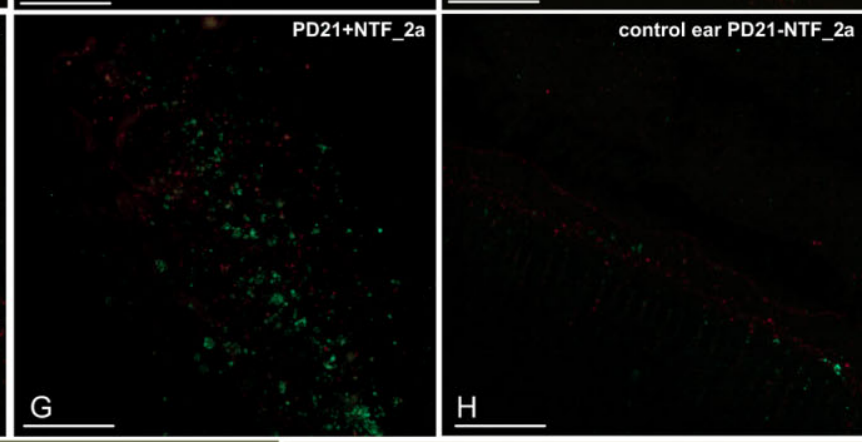

G

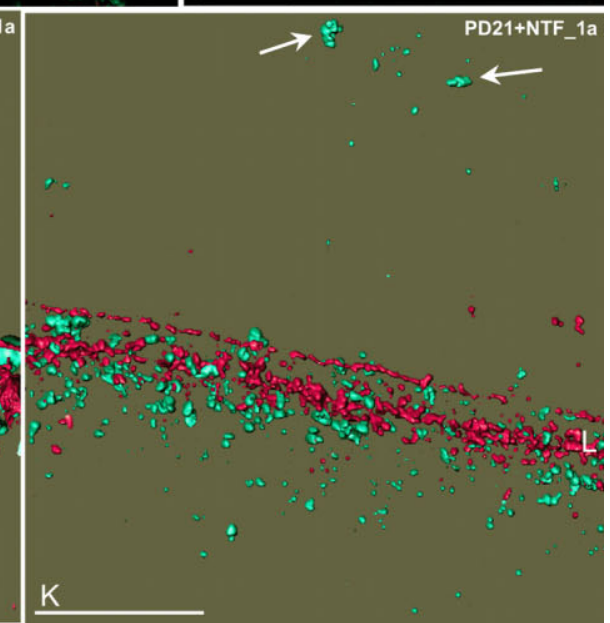

Fig. 6. A-K: Effect of BDNF/aFGF treatment on peripheral processes. Parvalbumin LI green, synaptophysin LI magenta. Immediate (A-D) and delayed (E,F) NTF treatment results in higher immunoreactivity for parvalbumin (green), with more widespread puncta along the cochlear spiral compared with corresponding contralateral ears of

the same individual (B,D,F,H). Isosurface rendering of confocal image stacks (I-K) clearly visualizes size and localization of immunoreactivities in normal hearing (I) and immediately (J)- and delayed (K)-NTF treated animals. The PD21 + BDNF ear shows tendencies for a more distal spread of parvalbumin LI (K, arrows). Scale bars $=50 \mu \mathrm{m}$.
8C). Often these afferent fibers showed swellings as they entered the scar tissue, reminiscent of afferent terminals beneath IHC in normal hearing animals that often swell due to glutamate toxicity. Karnovsky-fixed tissue confirmed the presence of nerve fibers in the inner sulcus displaying typical morphologic characteristics (Fig. 8D).

Although no effects of NTF treatment on synaptophysin immunostaining were noted in immunofluorescencelabeled surface preparations, differences were found in immunoperoxidase-labeled plastic sections. Positive synaptophysin immunostaining was present in the vicinity of inner pillar remnants and in the osseous spiral lamina (Fig. 9A) in animals with and without NTF treatment. However, only in animals with NTF treatment and thicker scar tissue was synaptophysin immunolabeling observed in the inner sulcus region (Fig. 9B,C) as well as in "bulges" of tissue in the mesothelial layer lining the scala tympani (Fig. 9B). TEM confirmed synaptophysin LI to be assigned to nerve fibers (Fig. 9D).

\section{SGN: changes with deafness and influence of BDNF/aFGF}

The number of SGN progressively decrease over time following deafening in untreated animals (Figs. 10, 11). A base-apex gradient in the onset of loss is evident, with decreases appearing more rapidly in basal turns. There is a $50 \%$ decrease across turns at 47 days following deafening. In the group of animals receiving BDNF and aFGF for 
The Journal of Comparative Neurology. DOI 10.1002/cne

AFFERENT REGENERATION WITH INTRASCALAR BDNF AND AFGF

TABLE 1. Semiquantitative Volumetric Assessment of Parvalbumin LI in NTF-Treated Animals in the Basal Turn ${ }^{1}$

\begin{tabular}{|c|c|c|c|c|c|c|}
\hline Specimen & $\Sigma \mathrm{V}_{\text {parv }} / \mu \mathrm{m}$ & Puncta/100 $\mu \mathrm{m}$ & Specimen & $\Sigma \mathrm{V}_{\text {parv }} / \mu \mathrm{m}$ & Puncta/100 $\mu \mathrm{m}$ & $t$-Test $\Sigma \mathrm{V}_{\text {parv }}$ \\
\hline 1: PD3 + NTF & 12.7 & 38.9 & 1: PD3-NTF & 5.2 & 22.2 & 0.023 \\
\hline 2: $\mathrm{PD} 3+\mathrm{NTF}$ & 24.4 & 60.6 & 2: PD3-NTF & 7.3 & 12.5 & $<0.001$ \\
\hline 3: PD3 + NTF & 37.0 & 59.0 & 3: PD3-NTF & 5.1 & 14.6 & 0.022 \\
\hline 4: PD21 + NTF & 15.7 & 43.7 & 4:PD21-NTF & 7.0 & 25.4 & 0.003 \\
\hline 5: PD21 + NTF & 24.8 & 52.1 & 5:PD21-NTF & 7.1 & 24.8 & 0.006 \\
\hline 6: PD21 + NTF & 12.7 & 28.1 & 6:PD21-NTF & 2.6 & 13.6 & $<0.001$ \\
\hline
\end{tabular}

${ }^{1}$ Isosurface rendering and calculation of the volume of parvalbumin-LI per micrometer organ of Corti ( $\Sigma V$ parv/ $\mu$ m) of three specimens immediately treated with NTF (specimens 1-3; PD3 + NTF) and three animals with delayed neurotrophic treatment (specimens 4-6; PD21 + NTF). Contralateral untreated ears of the same individual are given alongside (PD3 - NTF and PD21 - NTF ). The number of parvalbumin puncta (puncta/100 $\mu \mathrm{m}$ organ of Corti) are given for each cochlea. Turns 1a and 1b were used for this assessment. Student's $t$-test served to assess whether the $\Sigma V$ parv/ $\mu$ m values for contralateral ears are statistically different from each other $\left(t\right.$-test $\left.\Sigma V_{\text {parv }}\right)$.

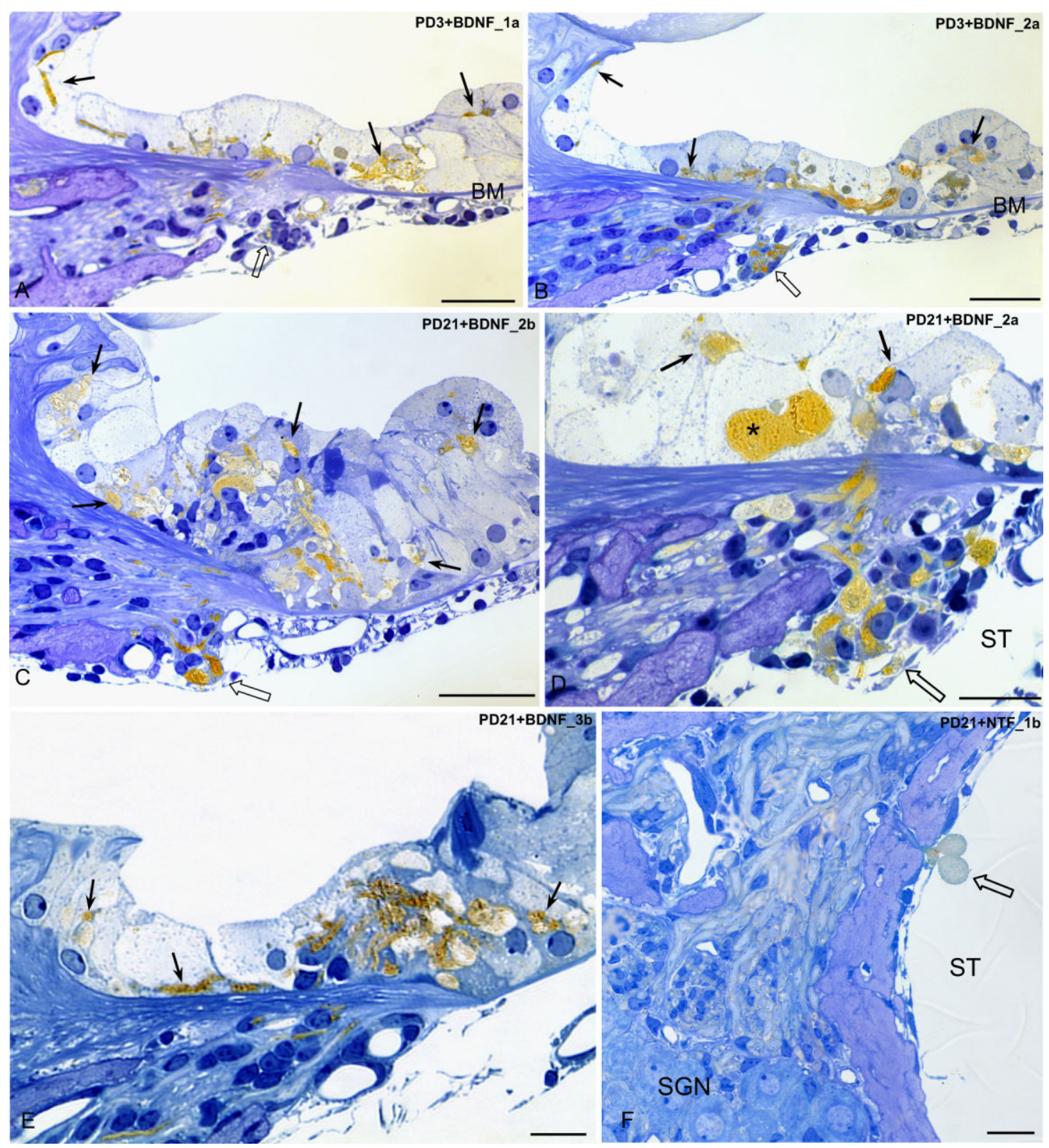

Fig. 7. Regrowth of nerve fibers. Semithin sections of NTF-treated ears processed for immunohistochemistry to detect parvalbumin $(\mathrm{F}, \mathrm{neg}-$ ative control). Immediate treatment $(\mathbf{A}, \mathbf{B})$ and delayed administration (C-F) of BDNF/aFGF results in immunopositive fibers within the scar formation of the former sensory epithelium (solid arrows) as well as in newly formed tissue bulging into scala tympani (open arrows). This could be observed in the basal (A,C) as well as the middle (B,D) turn, in some animals also in the apex (E). Single nerve fibers even penetrate through canaliculi perforantes at the modiolar wall into scala tympani (F). Scale bars $=20 \mu \mathrm{m}$ in $\mathrm{A}-\mathrm{C}, \mathrm{F} ; 10 \mu \mathrm{m}$ in $\mathrm{D}, \mathrm{E}$ 

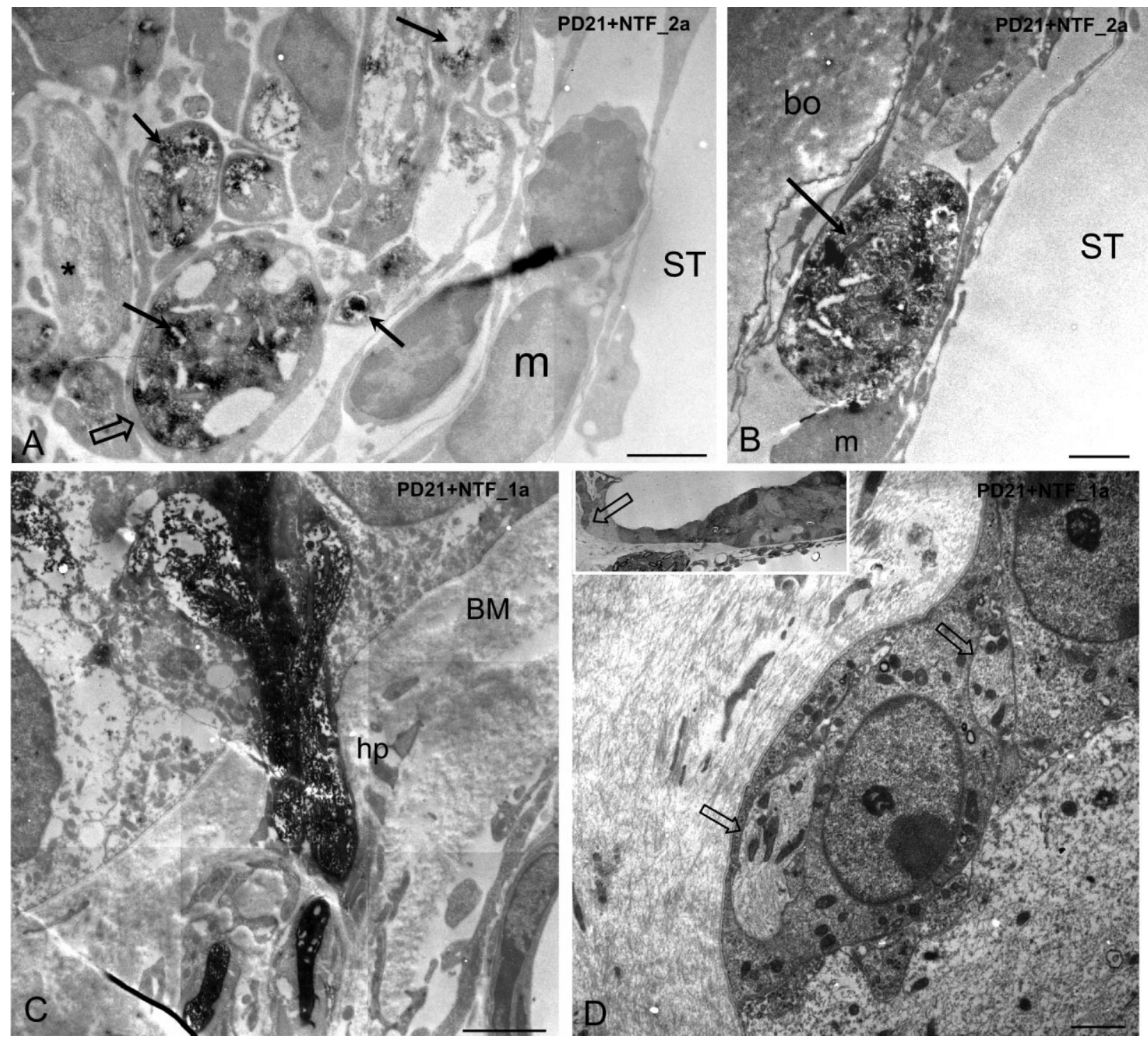

Fig. 8. Regrowth of afferent nerve fibers: transmission electron microscopy. Parvalbumin LI in PD21 + NTF cochleae (A-C). A,B: Within newly formed tissue bulging into the scala tympani (ST), immunoreactivity can be assigned to nerve fibers. A: Some fibers are negative (asterisk), but most show immunostaining (solid arrows). Regrown nerve fibers are bordered by a mesothelial cell (m) sheet lining perilymphatic spaces. Fibers are ensheathed by satellite cells (open arrows) that do not contain myelin layers. B: A single parvalbumin-positive fiber (a) travels in a spiral direction between the

bony modiolar wall (bo) and the mesothelial cell sheet (m). C: As nerve fibers penetrate the basilar membrane $(\mathrm{BM})$ via the habenula perforata (hp), afferent peripheral processes often show swelling, comparable to artifacts on afferent terminals below IHC in normal hearing animals (not shown). D: Karnovsky's fixation demonstrates fibers in the inner sulcus region (see inset showing a lower magnification overview; open arrow) to be neuronal structures with typical morphology for nerve fibers (open arrows). Scale bars $=2 \mu \mathrm{m}$ in A,B,D; $5 \mu \mathrm{m}$ in $\mathrm{C}$.

26 days starting 21 days following deafening, there was no significant loss of SGN in all turns. Immediately-treated animals show some loss of SGN compared with normal, most pronounced in the upper turns (Fig. 10). Both NTFtreated groups show a significant increase of SGN density compared with untreated deafened cochleae or animals receiving artificial perilymph. Moreover, in delayed-NTFtreated animals, mean SGN density in the basal turn was even higher than in normal hearing subjects (normal = 1,425 SGN $\backslash \mathrm{mm}^{2}$; PD21 + NTF $=1,675 \mathrm{SGN} \backslash \mathrm{mm}^{2} ; P<$ 0,001). Middle and upper turns in the PD21 + NTF ears had SGN densities comparable to those of normal hearing

animals. The treatment was less effective in animals with treatment starting at 3 days following deafness, where there was less survival. Contralateral ears from NTFtreated animals (PD3 - NTF and PD21 - NTF) and corresponding control animals (PD29 and PD47) did not show any significant difference in SGN density, suggesting no contralateral effect of the neurotrophic drugs. Data and significant differences between selected animal groups are summarized in Figure 10.

An increase in spiral ganglion size has been reported with BDNF treatment (McGuinness and Shepherd, 2005). The current study showed a trend toward an increase in 

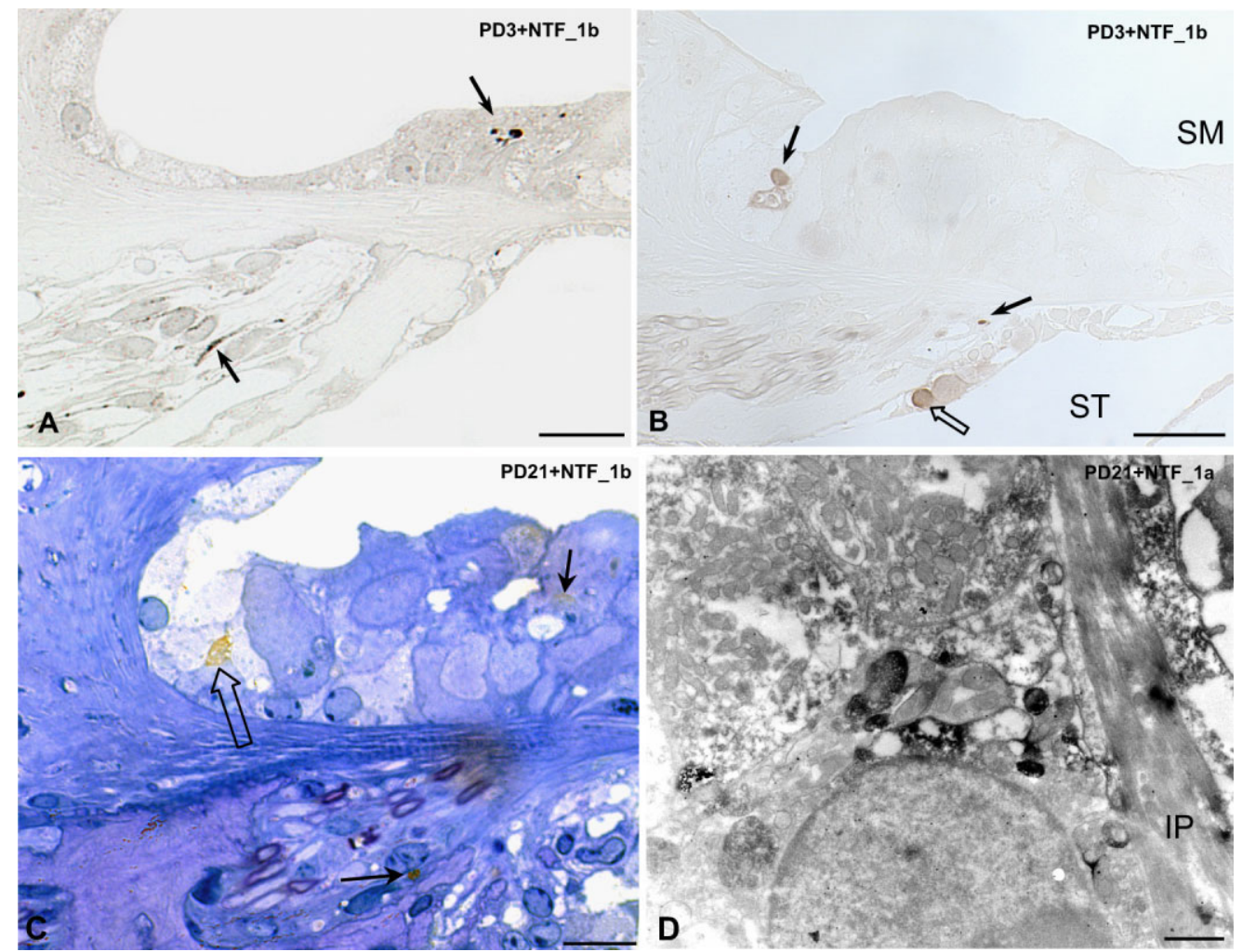

Fig. 9. Synaptophysin LI with neurotrophic treatment. A-C: Semithin sections. D: Electron micrograph. Synaptophysin immunostaining is present in most animals only in the former region of the inner spiral bundle and tunnel spiral bundle (A,D).
Some animals show immunostaining also at the inner sulcus (arrows, $\mathrm{B}, \mathrm{C}$ ) and regrown fibers adjacent to the scala tympani (open arrows, B) and show weak synaptophysin LI. Scale bars $=20 \mu \mathrm{m}$ in $\mathrm{A} ; 30 \mu \mathrm{m}$ in $\mathrm{B} ; 10 \mu \mathrm{m}$ in $\mathrm{C} ; 1 \mu \mathrm{m}$ in $\mathrm{D}$.
SGN size in the basal turn of cochleae from animals receiving BDNF and aFGF starting either 3 days or 21 days following deafening (Fig. 12). Delayed NTF treatment resulted in increased ganglion size throughout all cochlear turns. Immediate treatment resulted in larger neurons only in the basal turn and decreased mean diameters in more apical turns compared with normal. Data and significant differences between selected animal groups are summarized in Figure 12. Quantification of Rosenthal's canal and blood vessel area did not show any significant difference among animal groups.

Qualitative comparison of delayed NTF treatment and its untreated control group 8 (PD47) demonstrates a striking effect of BDNF and aFGF (Fig. 13). Different stages of apoptosis in several neurons and large intercellular spaces distinguish the spiral ganglion of untreated animals from NTF exposition with big neurons that squeeze into available spatial gaps in Rosenthal's canal. Aggregation or loose distribution of Nissl bodies within cytoplasm could be detected in all animal groups, comparable to that in normal hearing animals. Increased perikaryal size goes together with larger nuclei (approximately 10-15\%; 100 SGN measured).

Electron microscopy of Karnovsky's-fixed tissue reveals only few aberrant morphologic structures at the subcellular level. In type I neurons, distribution and cytoplasmatic content such as Nissl substance, mitochondria, and ribosomes resemble those in normal control animals (Fig.

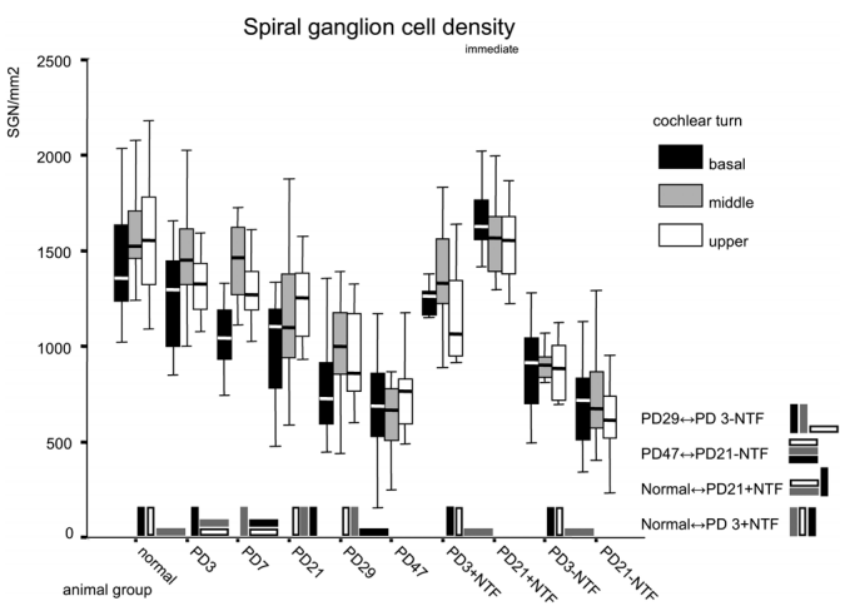

Fig. 10. Quantitative analysis of spiral ganglion neurons in basal, middle, and apical turns. Box blot diagram of SGC density (number of SGN/area Rosenthal's excluding blood vessels). Immediate (PD3 + BDNF) and delayed (PD21 + BDNF) neurotrophic treatment results in significantly higher densities compared with control groups or contralateral untreated ears. A base-apex gradient of neuronal degeneration is obvious. SGC density in the basal turn of PD21 + BDNF ears is even higher than in normal hearing animals. Vertical bars indicate a statistically significant difference between adjacent animal groups; horizontal bars display no statistically significant difference. Selected comparisons are beside the graph. 

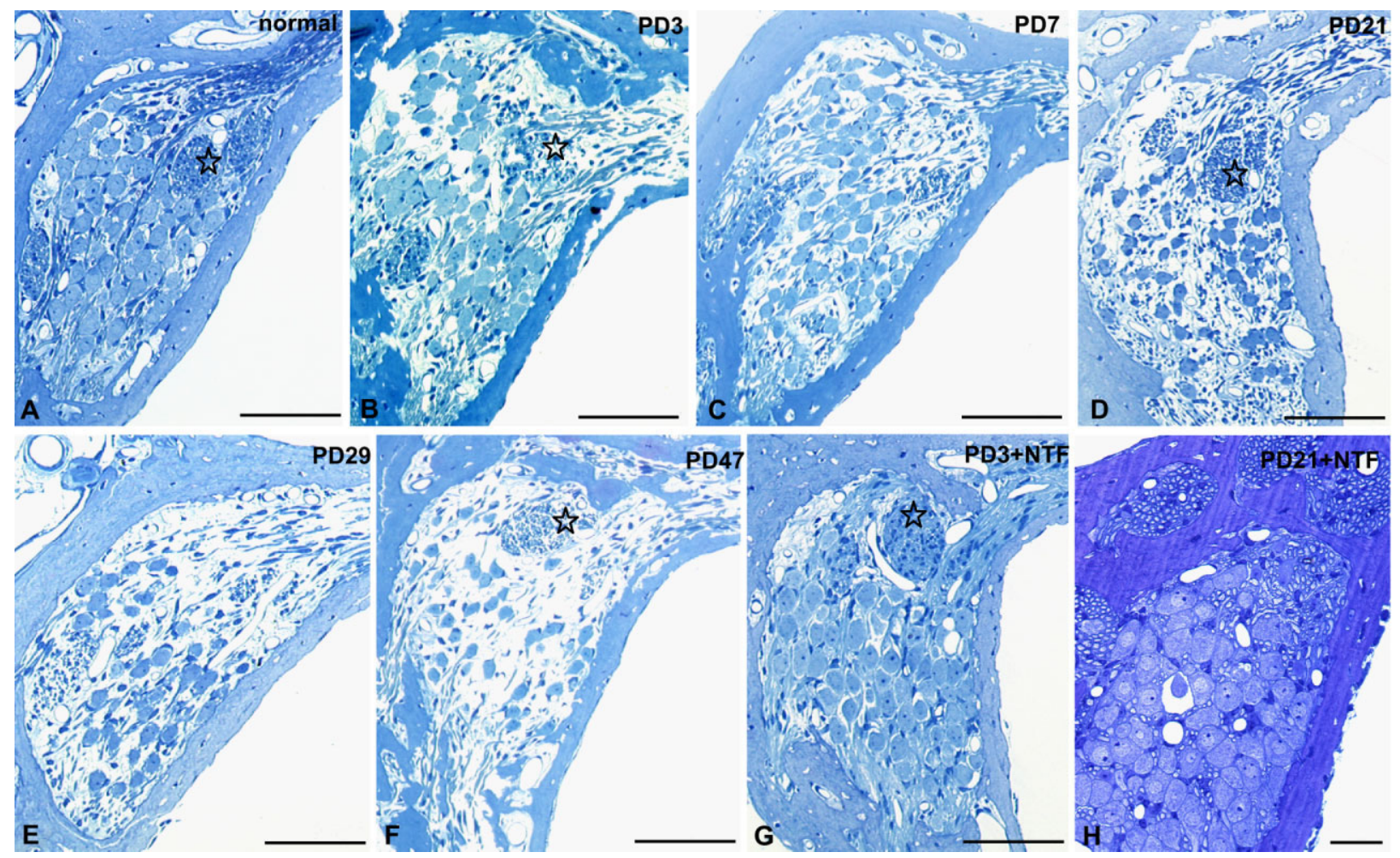

Fig. 11. A-H: Spiral ganglion cell degeneration and NTF treatment. Radial semithin section through the midportion of the modiolus showing Rosenthal's canal in the lower basal (1a) turn of normal (A), deafened $(\mathrm{B}-\mathrm{F})$, and neurotrophin-treated $(\mathrm{G}, \mathrm{H})$ animals. The spiral canal is filled with primary neurons sending their peripheral processes to the osseous spiral lamina. The intraganglionic spiral bun- dles containing spirally running efferent nerve fibers are marked with a star. From PD3 to PD47, SGN number decreases dramatically. Immediate and delayed NTF administration results in high neuron density and increased cell size. Scale bars $=100 \mu \mathrm{m}$ in A-G; $50 \mu \mathrm{m}$ in $\mathrm{H}$. [Color figure can be viewed in the online issue, which is available at www.interscience.wiley.com]
14A). Myelin layers are reduced in delayed-NTF-treated and control animals (PD21; approximately 8-12 layers) compared with normal (13-22 layers). Myelin sheath of axons in Rosenthal's canal appears normal (Fig. 14). SGN with densely packed neurofilaments, referred to as type II cells, show high amounts of NMissl bodies in their enlarged perikarya (Fig. 14B).

\section{DISCUSSION}

Our results are consistent with earlier reports showing a rapid regression of afferent auditory nerve peripheral processes within days following their deafferentation consequent to loss of IHC. On the other hand, medial and lateral olivocochlear efferent peripheral processes were found to be maintained for many weeks following the loss of their targets, OHC and auditory nerve peripheral processes, respectively. Our study is the first to use selective markers to differentiate the effects of neurotrophic factors on afferent vs. efferent peripheral processes after deafening. Our results show the greatest effect on afferents, providing a significant regrowth of afferent peripheral processes. The effect on efferent peripheral processes was more subtle. Chronic BDNF/aFGF did not provide for enhanced maintenance of efferents, with the loss of efferent peripheral processes occurring on a similar time scale in treated and untreated animals. Treated animals, however, did have buds of efferent fibers entering into scala tympani as well as fibers in atypical positions, such as the inner sulcus (not shown), which was not found in untreated animals, suggesting an influence.

\section{Afferents}

The kanamycin plus ethacrynic acid deafening condition produces a rapid loss of IHC and OHC; however, we do find parvalbumin staining of the few remaining IHC 3 days following this treatment. This may represent IHC remnants or IHC with delayed cell death. The observation that no remaining IHC are observed at later periods following deafening is consistent with either explanation. BDNF/aFGF treatment did not enhance IHC survival, consistent with the study by Shoji et al. (2000) showing that, although several other neurotrophic factors enhanced IHC survival following noise or ototoxic drugs, BDNF was not effective. Yamasoba et al. (2001) showed that FGF was also not effective in protecting hair cells. BDNF/aFGF treatment did provide a dramatic effect on afferent processes. Chronic BDNF/aFGF resulted in a significantly increased number of afferent peripheral processes even after a 3-week delay, comparable to what Wise et al. (2005) described with BDNF/NT-3 treatment using a neurofilament stain to identify fibers. Our study used a specific marker for afferents and provides support for the idea that most of what Wise et al. described were indeed afferent processes. 


\section{Spiral ganglion cell diameter}

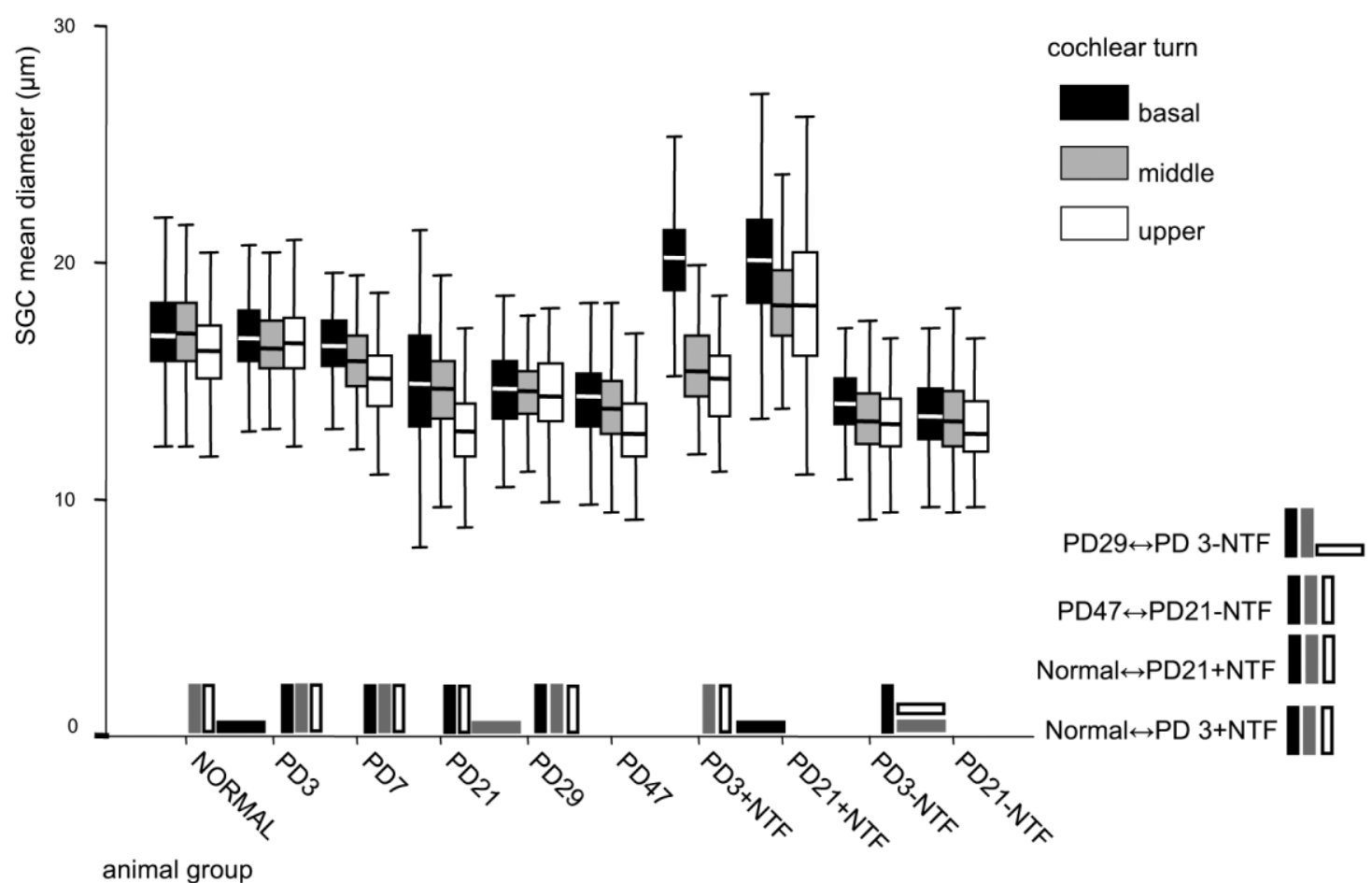

Fig. 12. Quantitative analysis of spiral ganglion cell diameter. Box blot chart of SGC diameter (arithmetic mean of longest and shortest diameter). Whereas deafening results in a decrease in SGN diameter, neurotrophic treatment provokes an increase in the basal turn, and delayed NTF treatment leads to increased neuron size throughout all

cochlear turns. Vertical bars indicate a statistically significant difference between adjacent animal groups; horizontal bars display no statistically significant difference. Selected comparisons are given below.

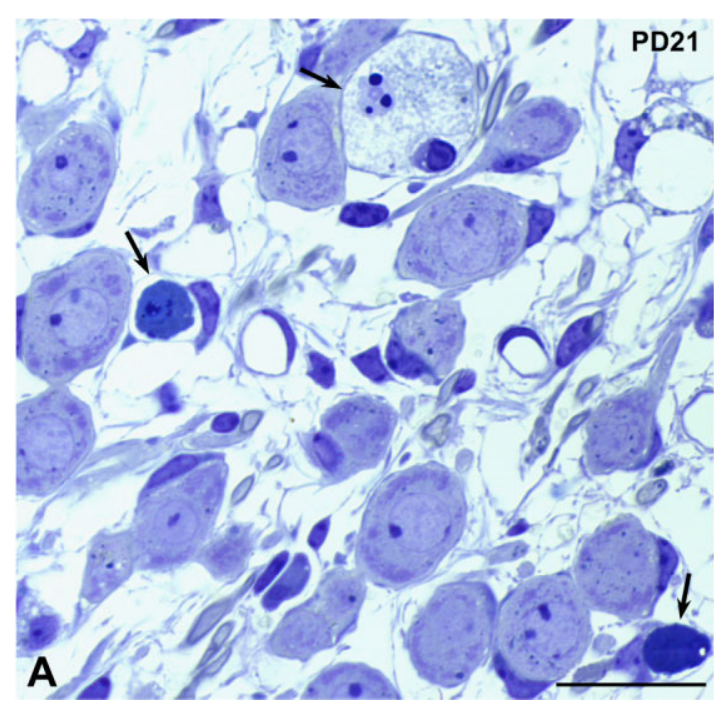

Fig. 13. Neurotrophic effect on spiral ganglion neurons in delayedtreatment animals (semithin sections of the upper basal turn 1b). Three weeks postdeafening (A) shows considerable loss of neurons. Several apoptotic stages of degenerating neurons can be detected (arrows). Subsequent administration of BDNF and aFGF visualizes

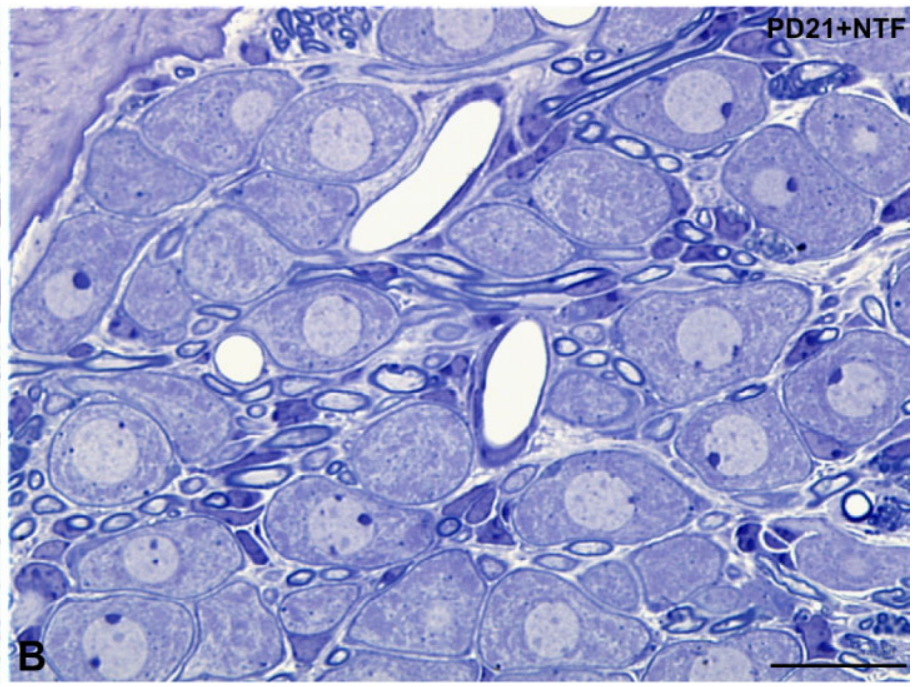

the impressive effect of delayed NTF treatment (B), with large neurons that crowd in Rosenthal's canal. Scale bars $=25 \mu \mathrm{m}$. [Color figure can be viewed in the online issue, which is available at www. interscience.wiley.com] 


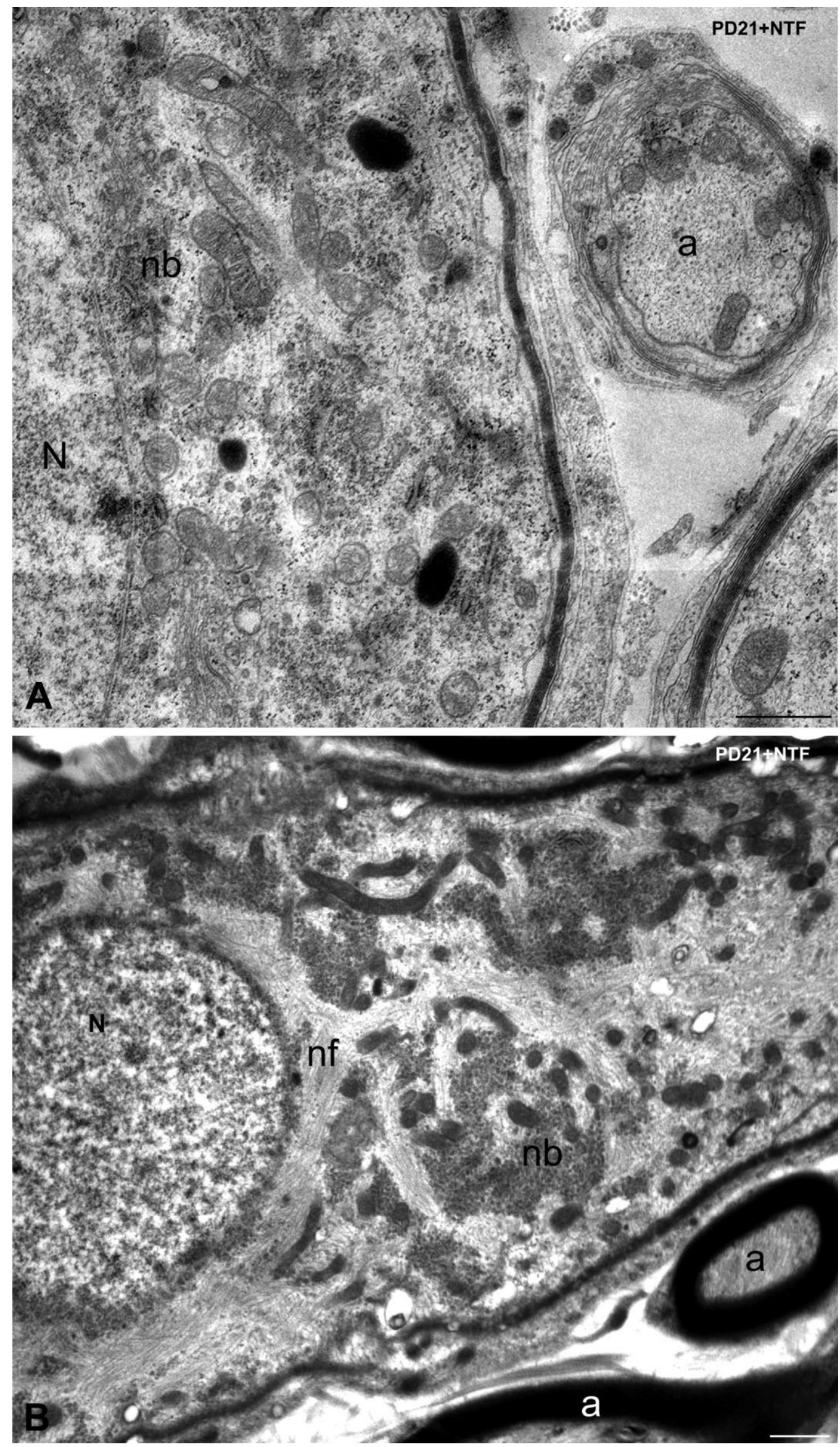

Fig. 14. Neurotrophic effect on SGN (electron microscopy). A: Ultrastructure gives indication of high cellular metabolism in type I ganglion neurons with loose chromatin in the nucleus $(\mathrm{N})$ and high amounts of Nissl bodies (nb) that show normal distribution and no pathological aggregation within the cell. a, Axon. B: Putative type II ganglion neuron. The high amount of neurofilaments (nf) leads to an aggregation of Nissl bodies (nb) that appear more dense than in type I neurons. Six to ten myelin layers characterize the perikarya of NTF-treated animals compared with 12-16 layers in normal hearing animals. Axonal myelinization varies within the same section considerably from loose (A) to very dense (B), comparable to the case in normal hearing animals. Scale bars $=1 \mu \mathrm{m}$. 
Developmental studies show that BDNF and FGF not only induce the normal connection between auditory neurons and IHC but also act to direct it (Ernfors et al., 1995; Staecker et al., 1996; Hossain et al., 1997, 2002; Dazert et al., 1998; Aletsee et al., 2003; Fritzsch et al., 2004). It is therefore interesting to see the direction and placement of regrown fibers under our experimental conditions, with BDNF and aFGF delivered chronically into basal scala tympani. If $\mathrm{BDNF}$ and $\mathrm{aFGF}$ act not only to induce regrowth but also to attract it, one might expect afferent fiber regrowth into scala tympani. In the current study, we found many parvalbumin-immunolabeled fibers sprouting into scala tympani, but these remained in close proximity to the osseous or membranous spiral lamina (basilar membrane) and did not traverse through scala tympani. This is consistent with earlier reports with different NTF combinations (Altschuler et al., 1999; Wise et al., 2005). Some fibrosis in the scala tympani enhanced outgrowth of fibers. This suggests that, even with an attraction cue, the afferent fibers might still need some tissue or cellular template to promote growth. It is interesting that in our study outgrowth into the scala tympani was seen more frequently in the second turn than in the basal turn. This suggests that a concentration or a concentration gradient might play a role in attracting nerve fibers to sprout into perilymphatic spaces.

Most of the regrowth observed in the current study was into the remaining tissue above the osseous or membranous spiral lamina. Parvalbumin-immunolabeled afferent fibers ran toward the location of their former target (IHC) in the epithelial scar, more medially into the epithelium of the inner sulcus, and also in distal region toward the outer sulcus as far as tectal cells. This is comparable to what was reported by Wise et al. (2005) with BDNF, NT3, and a neurofilament stain.

In the normal cochlea, peripheral processes lose their myelin sheath as they exit through the habenula perforata into the tissue of the organ of Corti to connect with IHC. The "regrown" fibers that enter scar tissue or remaining supporting cells above the osseous and membranous spiral lamina appear to follow the same pattern and are unmyelinated after their exit from habenula perforata. On the other hand, there are satellite cells that show morphology of typical Schwann cells associated with the outgrowths that bulge into the scala tympani but no myelin layers. In the newly formed bulge close to the osseous spiral lamina, within canaliculi perforantes near Rosenthal's canal and fibrous tissue in the scala tympani, nerve fibers are myelinated, suggesting the myelinization process is unimpaired.

\section{Efferents}

Efferents are maintained despite their loss of targets. Whereas McFadden et al. (2004) reported complete loss of efferents in the basal turn by 21 days following gentamycin/ethacrynic acid deafening in the chinchilla, we found excellent survival until 47 days following a comparable kanamycin/ethacrynic acid deafening in the guinea pig model. There was a significant loss in the medial efferent system, beginning at the site of the outermost row of $\mathrm{OHC}$, but no major loss in the inner and tunnel spiral bundle ascribed to lateral efferents. Although medial efferents are reduced in the scar region of the basal turn, there are still many myelinated and unmyelinated fibers in the intraganglionic spiral bundle, suggesting that medial and lateral efferent fibers, respectively, are still present at this position but may be traveling more toward the apex.

Efferent peripheral processes are not lost immediately following loss of their target, so it is interesting to consider what changes might underlie their loss 5-7 weeks later. One clue could be the base-apex gradient to the timing of the loss, as previously reported by McFadden et al. (2004). The loss of efferent processes occurs first in more basal turns, where the hair cell loss and the progression of scar formation are more rapid. Scar formation also occurs more rapidly in the $\mathrm{OHC}$ region than more medially. Loss of efferents might then be associated with the progression of scar formation and the "flattening" of the scar that occurs over time with loss of the supporting cells and their replacement with squamous epithelium. This goes together with a more flat scar formation in the basal turn. In untreated deafened animals, we found the timing of efferent loss to be associated with the latest stage of scar formation. It may be that the appearance of the late-stage scar occurs at different rates in different deafness models (McFadden et al., 2004) and the timing of late-term scar will coincide with loss of efferents in different deafness models. On the other hand, this would predict that, if the formation of a late-term scar is delayed, then efferent loss would also be delayed. We found that the chronic administration of $\mathrm{BDNF} / \mathrm{aFGF}$ slows down the progression of scar formation, so that at 47 days following deafness there is only an intermediate-stage scar. Nonetheless, there is no enhanced maintenance of efferents with the efferent loss in BDNF/aFGF-treated animals at 47 days following deafness equivalent to loss in the nontreated deafened animals.

In deafened untreated animals during the period before efferent loss, synaptophysin-immunolabeled efferents are observed in their original positions, despite loss of targets. It is only in deafened animals receiving BDNF and aFGF that sprouting of synaptophysin-labeled fibers into the inner sulcus or under the osseous or membranous spiral lamina is observed. Despite this sprouting and growth of efferent fibers, there was no significant increase in their maintenance, with loss of synaptophysin immunostaining occurring at comparable times and in comparable amounts in treated and untreated animals.

Studies by Strominger et al. (1995) showed regeneration of nerve fibers following an octave-band noise overstimulation perhaps induced by endogenous factors produced by the remaining normal elements adjacent to the lesion. This study used acetycholinesterase staining as an efferent marker and concluded that regenerated nerve fibers were not efferent. This is consistent with our results indicating that the major regrowth induced by neurotrophic factors is of afferent processes.

\section{Efferent/afferent connections}

In the normal cochlea, the lateral olivocochlear efferents make synaptic contacts with the peripheral processes of afferents. Under conditions where there is regrowth of peripheral processes, there is potential for the remaining lateral efferents to reconnect with the newly appearing afferent processes. Most of the fixation conditions used in the present study to allow preembedding immunostaining are not optimal for synapse identification, and we were not able to identify synaptic contact between efferents and afferents. It would be interesting in future studies to in- 
vestigate whether synaptic connections are reformed and, if not, to develop interventions to promote this reconnection. The LOC system normally acts to give different set points to different afferents, increasing the dynamic range of the auditory nerve. If remaining LOC efferents could be made to reconnect to regenerated afferents and this connection maintained, perhaps they could reestablish the increased dynamic range and this could be taken advantage of by cochlear prostheses.

\section{SGN}

BDNF/aFGF enhanced the survival of SGN, even after a 3 -week delay, consistent with what has been previously reported with BDNF (Staecker et al., 1996; Miller et al., 1997; McGuinness and Shepherd, 2005), BDNF/NT-3 (Wise et al., 2005), BDNF/CNTF (Shinohara et al., 2002; Yamagata et al., 2004), or GDNF (Ylikoski et al., 1998; Miller et al., 2002). McGuinness and Shepherd (2005) reported an increase in the size of SGN following BDNF treatment, and the present study found a similar result with BDNF/aFGF. There was also an increase in the density of SGN cells in the profiles through Rosenthal's canal. There was no change in the size of the profile of Rosenthal's canal and no augmentation of blood vessels (on the basis of blood vessel area measurements), suggesting there was an increased number of SGN. It is possible that the increases in cell size influenced the metric for assessment of density. It is also possible that there is a movement of SGN, compressing more cells into the same space, although we did not find decreased densities of neurons in more apical turns in the delayed-NTF-treated group. Another possible explanation is that new SGN developed from endogenous progenitor/stem cells, which have recently been identified in the human modiolus (Rask-Andersen et al., 2005) as well as mouse cochlea and vestibule (Martinez-Monedero et al., 2007; Senn et al., 2007) under the conditions of deafening, SGN loss, and BDNF/aFGF treatment.

\section{ACKNOWLEDGMENTS}

Amgen Corporation generously provided the BDNF. We are grateful to Noel Wys, Susan DeRemer, Hollie Valentine, and Karolina Wesolowski for their technical assistance and Dr. Gunde Rieger for additional electron microscopy. Western blot data on the antiparvalbumin antibody were kindly provided by Prof. Marco Celio, Division of Anatomy, University of Fribourg.

\section{LITERATURE CITED}

Aletsee C, Brors D, Mlynski R, Ryan AF, Dazert S. 2003. Branching of spiral ganglion neurites is induced by focal application of fibroblast growth factor-1. Laryngoscope 113:791-796.

Altschuler RA, Cho Y, Ylikoski J, Pirvola U, Magal E, Miller JM. 1999. Rescue and regrowth of sensory nerves following deafferentation by neurotrophic factors. Ann N Y Acad Sci 884:305-311.

Bichler E, Spoendlin H, Rauchegger H. 1983. Degeneration of cochlear neurons after amikacin intoxication in the rat. Arch Otorhinolaryngol 237:201-208.

Bohne BA. 1977. Growth of cochlear damage with increasing severity of exposure. Trans Sect Otolaryngol Am Acad Ophthalmol Otolaryngol 84:420-421.

Brown JN, Miller JM, Altschuler RA, Nuttall AL. 1993. Osmotic pump implant for chronic infusion of drugs into the inner ear. Hear Res 70:167-172.
Counter SA, Canlon B, Borg E, Aldskogius H. 1997. Pattern of synaptophysin immunoreactivity in the efferent nerve terminals of the guinea pig cochlea. Neurosci Lett 222:199-203.

Dazert S, Kim D, Luo L, Aletsee C, Garfunkel S, Maciag T, Baird A, Ryan AF. 1998. Focal delivery of fibroblast growth factor-1 by transfected cells induces spiral ganglion neurite targeting in vitro. J Cell Physiol 177:123-129.

Ernfors P, Van De WT, Loring J, Jaenisch R. 1995. Complementary roles of BDNF and NT-3 in vestibular and auditory development. Neuron 14:1153-1164.

Ernfors P, Duan ML, Elshamy WM, Canlon B. 1996. Protection of auditory neurons from aminoglycoside toxicity by neurotrophin-3. Nat Med 2:463-467.

Eybalin M, Ripoll C. 1990. [Immunolocalization of parvalbumin in two glutamatergic cell types of the guinea pig cochlea: inner hair cells and spinal ganglion neurons]. C R Acad Sci III 310:639-644.

Fritzsch B, Tessarollo L, Coppola E, Reichardt LF. 2004. Neurotrophins in the ear: their roles in sensory neuron survival and fiber guidance. Prog Brain Res 146:265-278.

Gil-Loyzaga P, Pujol R. 1988. Synaptophysin in the developing cochlea. Int J Dev Neurosci 6:155-160.

Gillespie LN, Clark GM, Bartlett PF, Marzella PL. 2003. BDNF-induced survival of auditory neurons in vivo: Cessation of treatment leads to accelerated loss of survival effects. J Neurosci Res 71:785-790.

Hawkins JE Jr, Engstroem H. 1964. Effect of Kanamycin on cochlear cytoarchitecture. Acta Otolaryngol Suppl 188.

Hossain WA, Rutledge A, Morest DK. 1997. Critical periods of basic fibroblast growth factor and brain-derived neurotrophic factor in the development of the chicken cochleovestibular ganglion in vitro. Exp Neurol 147:437-451.

Hossain WA, Brumwell CL, Morest DK. 2002. Sequential interactions of fibroblast growth factor-2, brain-derived neurotrophic factor, neurotrophin-3, and their receptors define critical periods in the development of cochlear ganglion cells. Exp Neurol 175:138-151.

Incesulu A, Nadol JB Jr. 1998. Correlation of acoustic threshold measures and spiral ganglion cell survival in severe to profound sensorineural hearing loss: implications for cochlear implantation. Ann Otol Rhinol Laryngol 107:906-911.

Johnsson LG, Hawkins JE Jr. 1976. Degeneration patterns in human ears exposed to noise. Ann Otol Rhinol Laryngol 85:725-739.

Jyung RW, Miller JM, Cannon SC. 1989. Evaluation of eighth nerve integrity by the electrically evoked middle latency response. Otolaryngol Head Neck Surg 101:670-682.

Knipper M, Zimmermann U, Rohbock K, Kopschall I, Zenner HP. 1995. Synaptophysin and GAP-43 proteins in efferent fibers of the inner ear during postnatal development. Brain Res Dev Brain Res 89:73-86.

Koitchev K, Guilhaume A, Cazals Y, Aran JM. 1982. Spiral ganglion changes after massive aminoglycoside treatment in the guinea pig. Counts and ultrastructure. Acta Otolaryngol 94:431-438.

Leake PA, Hradek GT. 1988. Cochlear pathology of long term neomycin induced deafness in cats. Hear Res 33:11-33.

Martinez-Monedero R, Oshima K, Heller S, Edge AS. 2007. The potential role of endogenous stem cells in regeneration of the inner ear. Hear Res.

McFadden SL, Ding D, Jiang H, Salvi RJ. 2004. Time course of efferent fiber and spiral ganglion cell degeneration following complete hair cell loss in the chinchilla. Brain Res 997:40-51.

McGuinness SL, Shepherd RK. 2005. Exogenous BDNF rescues rat spiral ganglion neurons in vivo. Otol Neurotol 26:1064-1072.

Miller JM, Chi DH, O’Keeffe LJ, Kruszka P, Raphael Y, Altschuler RA. 1997. Neurotrophins can enhance spiral ganglion cell survival after inner hair cell loss. Int J Dev Neurosci 15:631-643.

Miller JM, Miller AL, Yamagata T, Bredberg G, Altschuler RA. 2002. Protection and regrowth of the auditory nerve after deafness: neurotrophins, antioxidants and depolarization are effective in vivo. Audiol Neurootol 7:175-179.

Miller JM, Le Prell CG, Prieskorn DM, Wys NL, Altschuler RA. 2007. Delayed neurotrophin treatment following deafness rescues spiral ganglion cells from death and promotes regrowth of auditory nerve peripheral processes: effects of brain-derived neurotrophic factor and fibroblast growth factor. J Neurosci Res (in press).

Morest DK, Kim J, Potashner SJ, Bohne BA. 1998. Long-term degeneration in the cochlear nerve and cochlear nucleus of the adult chinchilla following acoustic overstimulation. Microsc Res Techniq 41:205-216.

Nadol JB Jr. 1977. Electron microscopic observations in a case of long- 
standing profound sensorineural deafness. Ann Otol Rhinol Laryngol 86:507-517.

Nadol JB Jr. 1990. Degeneration of cochlear neurons as seen in the spiral ganglion of man. Hear Res 49:141-154.

Nadol JB Jr. 1997. Patterns of neural degeneration in the human cochlea and auditory nerve: implications for cochlear implantation. Otolaryngol Head Neck Surg 117:220-228.

Nadol JB Jr, Young YS, Glynn RJ. 1989. Survival of spiral ganglion cells in profound sensorineural hearing loss: implications for cochlear implantation. Ann Otol Rhinol Laryngol 98:411-416.

Nadol JB Jr, Cho YB, Burgess BJ, Adams JC. 1993. The localization of synaptophysin in the organ of Corti of the human as shown by immunoelectron microscopy. Acta Otolaryngol 113:312-317.

Pack AK, Slepecky NB. 1995. Cytoskeletal and calcium-binding proteins in the mammalian organ of Corti: cell type-specific proteins displaying longitudinal and radial gradients. Hear Res 91:119-135.

Prieskorn DM, Miller JM. 2000. Technical report: chronic and acute intracochlear infusion in rodents. Hear Res 140:212-215.

Puel JL, Saffiedine S, Gervais dC, Eybalin M, Pujol R. 1995. Synaptic regeneration and functional recovery after excitotoxic injury in the guinea pig cochlea. C R Acad Sci III 318:67-75.

Puel JL, Ruel J, Gervais dC, Pujol R. 1998. Excitotoxicity and repair of cochlear synapses after noise-trauma induced hearing loss. Neuroreport 9:2109-2114.

Raphael Y, Altschuler RA. 1991. Scar formation after drug-induced cochlear insult. Hear Res 51:173-183.

Raphael Y, Altschuler RA. 1992. Early microfilament reorganization in injured auditory epithelia. Exp Neurol 115:32-36.

Rask-Andersen H, Bostrom M, Gerdin B, Kinnefors A, Nyberg G, Engstrand T, Miller JM, Lindholm D. 2005. Regeneration of human auditory nerve. In vitro/in video demonstration of neural progenitor cells in adult human and guinea pig spiral ganglion. Hear Res 203:180-191.

Roehm PC, Hansen MR. 2005. Strategies to preserve or regenerate spiral ganglion neurons. Curr Opin Otolaryngol Head Neck Surg 13:294-300.

Senn P, Oshima K, Teo D, Grimm C, Heller S. 2007. Robust postmortem survival of murine vestibular and cochlear stem cells. J Assoc Res Otolaryngol (in press).

Shepherd RK, Coco A, Epp SB, Crook JM. 2005. Chronic depolarization enhances the trophic effects of brain-derived neurotrophic factor in rescuing auditory neurons following a sensorineural hearing loss. J Comp Neurol 486:145-158.

Shinohara T, Bredberg G, Ulfendahl M, Pyykko I, Olivius NP, Kaksonen R, Lindstrom B, Altschuler R, Miller JM. 2002. Neurotrophic factor intervention restores auditory function in deafened animals. Proc Natl Acad Sci U S A 99:1657-1660.
Shoji F, Miller AL, Mitchell A, Yamasoba T, Altschuler RA, Miller JM 2000. Differential protective effects of neurotrophins in the attenuation of noise-induced hair cell loss. Hear Res 146:134-142.

Simmons DD, Moulding HD, Zee D. 1996. Olivocochlear innervation of inner and outer hair cells during postnatal maturation: an immunocytochemical study. Brain Res Dev Brain Res 95:213-226.

Soto-Prior A, Cluzel M, Renard N, Ripoll C, Lavigne-Rebillard M, Eybalin M, Hamel CP. 1995. Molecular cloning and expression of alpha parvalbumin in the guinea pig cochlea. Brain Res Mol Brain Res 34:337342 .

Spoendlin H. 1984. Factors inducing retrograde degeneration of the cochlear nerve. Ann Otol Rhinol Laryngol Suppl 112:76-82.

Spurr, AR. 1969. A low-viscosity epoxy resin embedding medium for electron microscopy. J Ultrastruct Res, v. 26, p31-43.

Staecker H, Kopke R, Malgrange B, Lefebvre P, Van de Water TR. 1996. NT-3 and/or BDNF therapy prevents loss of auditory neurons following loss of hair cells. Neuroreport 7:889-894.

Strominger RN, Bohne BA, Harding GW. 1995. Regenerated nerve fibers in the noise-damaged chinchilla cochlea are not efferent. Hear Res 92:5262.

Suzuka Y, Schuknecht HF. 1988. Retrograde cochlear neuronal degeneration in human subjects. Acta Otolaryngol Suppl 450:1-20.

Webster M, Webster DB. 1981. Spiral ganglion neuron loss following organ of Corti loss: a quantitative study. Brain Res 212:17-30.

Wise AK, Richardson R, Hardman J, Clark G, O’Leary S. 2005. Resprouting and survival of guinea pig cochlear neurons in response to the administration of the neurotrophins brain-derived neurotrophic factor and neurotrophin-3. J Comp Neurol 487:147-165.

Yagi M, Kanzaki S, Kawamoto K, Shin B, Shah PP, Magal E, Sheng J, Raphael Y. 2000. Spiral ganglion neurons are protected from degeneration by GDNF gene therapy. J Assoc Res Otolaryngol 1:315-325.

Yamagata T, Miller JM, Ulfendahl M, Olivius NP, Altschuler RA, Pyykko I, Bredberg G. 2004. Delayed neurotrophic treatment preserves nerve survival and electrophysiological responsiveness in neomycin-deafened guinea pigs. J Neurosci Res 78:75-86.

Yamasoba T, Altschuler RA, Raphael Y, Miller AL, Shoji F, Miller JM. 2001. Absence of hair cell protection by exogenous FGF-1 and FGF-2 delivered to guinea pig cochlea in vivo. Noise Health 3:65-78.

Ylikoski J, Pirvola U, Virkkala J, Suvanto P, Liang XQ, Magal E, Altschuler R, Miller JM, Saarma M. 1998. Guinea pig auditory neurons are protected by glial cell line-derived growth factor from degeneration after noise trauma. Hear Res 124:17-26.

Zimmermann CE, Burgess BJ, Nadol JB Jr. 1995. Patterns of degeneration in the human cochlear nerve. Hear Res 90:192-201. 